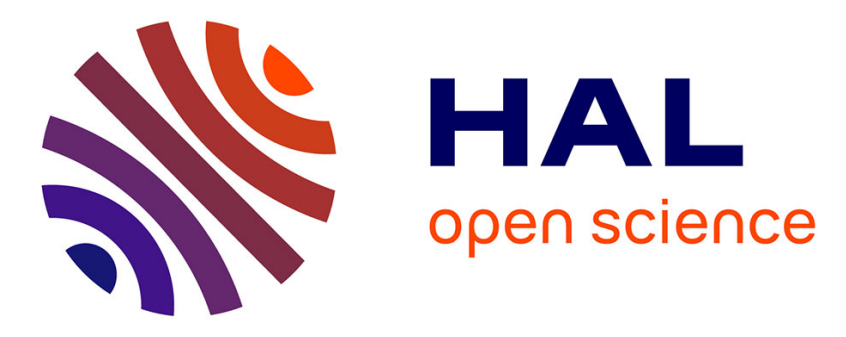

\title{
Validation of Aura Microwave Limb Sounder BrO observations in the stratosphere
}

\author{
L. J. Kovalenko, N. L. Livesey, R. J. Salawitch, C. Camy-Peyret, M. P. \\ Chipperfield, R. E. Cofield, M. Dorf, B. J. Drouin, L. Froidevaux, R.A. Fuller, \\ et al.
}

\section{To cite this version:}

L. J. Kovalenko, N. L. Livesey, R. J. Salawitch, C. Camy-Peyret, M. P. Chipperfield, et al.. Validation of Aura Microwave Limb Sounder $\mathrm{BrO}$ observations in the stratosphere. Journal of Geophysical Research: Atmospheres, 2007, 112 (24), pp.D24S41. 10.1029/2007JD008817 . hal-00200541

\section{HAL Id: hal-00200541 \\ https://hal.science/hal-00200541}

Submitted on 18 Feb 2016

HAL is a multi-disciplinary open access archive for the deposit and dissemination of scientific research documents, whether they are published or not. The documents may come from teaching and research institutions in France or abroad, or from public or private research centers.
L'archive ouverte pluridisciplinaire HAL, est destinée au dépôt et à la diffusion de documents scientifiques de niveau recherche, publiés ou non, émanant des établissements d'enseignement et de recherche français ou étrangers, des laboratoires publics ou privés. 


\title{
Validation of Aura Microwave Limb Sounder BrO observations in the stratosphere
}

\author{
L. J. Kovalenko, ${ }^{1}$ N. L. Livesey, ${ }^{1}$ R. J. Salawitch, ${ }^{1,2}$ C. Camy-Peyret,${ }^{3}$ M. P. Chipperfield, ${ }^{4}$ \\ R. E. Cofield, ${ }^{1}$ M. Dorf, ${ }^{5}$ B. J. Drouin, ${ }^{1}$ L. Froidevaux, ${ }^{1}$ R. A. Fuller, ${ }^{1}$ F. Goutail, ${ }^{6}$ \\ R. F. Jarnot, ${ }^{1}$ K. Jucks, ${ }^{7}$ B. W. Knosp, ${ }^{1}$ A. Lambert, ${ }^{1}$ I. A. MacKenzie, ${ }^{8}$ K. Pfeilsticker, ${ }^{5}$ \\ J.-P. Pommereau, ${ }^{6}$ W. G. Read, ${ }^{1}$ M. L. Santee, ${ }^{1}$ M. J. Schwartz, ${ }^{1}$ W. V. Snyder, ${ }^{1}$ \\ R. Stachnik, ${ }^{1}$ P. C. Stek, ${ }^{1}$ P. A. Wagner, ${ }^{1}$ and J. W. Waters ${ }^{1}$ \\ Received 13 April 2007; revised 6 September 2007; accepted 22 October 2007; published 20 December 2007.
}

[1] Validation of stratospheric BrO vertical profiles obtained by the Microwave Limb Sounder (MLS) on the Aura satellite is discussed. MLS BrO measurements are compared with expectations of its latitudinal and seasonal dependence, as well as with more localized balloon-borne measurements of $\mathrm{BrO}$. We describe the expected precision and systematic errors of the version 2.2 retrieval and show that scientific studies using MLS $\mathrm{BrO}$ vertical profiles require extensive averaging to increase the signal-to-noise ratio to useful values. A monthly zonal mean over a $10^{\circ}$ latitude bin (about 3,000 individual profiles) results in a precision of approximately $\pm 4 \mathrm{ppt}$ ( $\sim 25 \%$ of a typical daytime signal). Moreover, it is necessary to take day/night differences to remove large biases. The pressure range over which the data are considered useful is 10 to $3.2 \mathrm{hPa}$. Over this range, the estimated accuracy in the day/night difference is about $\pm 20 \%$. The vertical resolution is $5.5 \mathrm{~km}$ for 10 to $3.2 \mathrm{hPa}$. Day/night differences are a good measure of daytime $\mathrm{BrO}$ from 10 to $4.6 \mathrm{hPa}$; for $3.2 \mathrm{hPa}$ the nonnegligible nighttime $\mathrm{BrO}$ needs to be accounted for. We infer total inorganic bromine $\left(\mathrm{Br}_{\mathrm{y}}\right)$ to be $22.1 \pm 5.5 \mathrm{ppt}$ on the basis of analysis of MLS measurements of BrO, which implies a contribution of $6.5 \pm 5.5 \mathrm{ppt}$ to stratospheric bromine from sources other than long-lived $\mathrm{CH}_{3} \mathrm{Br}$ and halons.

Citation: Kovalenko, L. J., et al. (2007), Validation of Aura Microwave Limb Sounder BrO observations in the stratosphere, J. Geophys. Res., 112, D24S41, doi:10.1029/2007JD008817.

\section{Introduction}

[2] Bromine monoxide $(\mathrm{BrO})$ is an important species in the destruction of stratospheric ozone, especially in the midlatitude lower stratosphere [e.g., Yung et al., 1980; Salawitch et al., 2005; Sinnhuber et al., 2006; World Meteorological Organization (WMO), 2007]. Model studies estimate that catalytic cycles involving $\mathrm{BrO}$ account for up to half of the chemical loss of polar ozone [e.g., McElroy et

\footnotetext{
${ }^{1}$ Jet Propulsion Laboratory, California Institute of Technology, Pasadena, California, USA.

${ }^{2}$ Now at Department of Atmospheric and Oceanic Science, University of Maryland, College Park, Maryland, USA.

${ }^{3}$ Laboratoire de Physique Moleculaire pour l'Atmosphere et l'Astrophysique, Universite Pierre et Marie Curie, Paris, France.

${ }^{4}$ Institute of Atmospheric Science, School of Earth and Environment, University of Leeds, Leeds, UK.

${ }^{5}$ Institute of Environmental Physics, University of Heidelberg, Heidelberg, Germany.

${ }^{6}$ Service d'Aeronomie, Centre National de la Recherche Scientifique, Verrieres-le-Buisson, France.

${ }^{7}$ Harvard-Smithsonian Center for Astrophysics, Cambridge, Massachusetts, USA.

${ }^{8}$ School of GeoSciences, University of Edinburgh, Edinburgh, UK.
}

Copyright 2007 by the American Geophysical Union. 0148-0227/07/2007JD008817 al., 1986; Frieler et al., 2006; WMO, 2007]. Yet there remains considerable uncertainty in the atmospheric abundance of $\mathrm{BrO}$ [WMO, 2007]. Bromine monoxide is the main daytime constituent $(\sim 50 \%)$ of stratospheric inorganic bromine $\left(\mathrm{Br}_{\mathrm{y}}\right)$. Since relatively few measurements have been made of the other constituents, $\mathrm{Br}_{\mathrm{y}}$ is typically estimated from stratospheric measurements of $\mathrm{BrO}$, combined with estimates of the other constituents from photochemical models (often constrained by simultaneous measurements of $\mathrm{NO}_{2}$ and $\mathrm{O}_{3}$ [e.g., Sioris et al., 2006]). One current problem is that estimates of $\mathrm{Br}_{\mathrm{y}}$ inferred from measurements of stratospheric $\mathrm{BrO}$ obtained by various satellite and balloon-borne instruments disagree, ranging from 18 to 25 ppt [WMO, 2007, chap. 2]. Moreover, estimates of $\mathrm{Br}_{\mathrm{y}}$ from measurements of stratospheric $\mathrm{BrO}$ exceed the amount (16-17 ppt) that can be provided by long-lived organic source gases $\left(\mathrm{CH}_{3} \mathrm{Br}\right.$ and halons $)$. It is currently thought that very short lived substances (VSLS), many of biogenic origin, are an additional source of stratospheric inorganic bromine that can reconcile the bromine budget [WMO, 2007, chap. 2].

[3] Here we present a validation of stratospheric measurements of BrO by the Microwave Limb Sounder (MLS) instrument [Waters et al., 2006] on the Aura satellite. This instrument has been measuring vertical profiles of $\mathrm{BrO}$ with 


\section{a) $650 \mathrm{GHz}$ (B11F spectral band)}
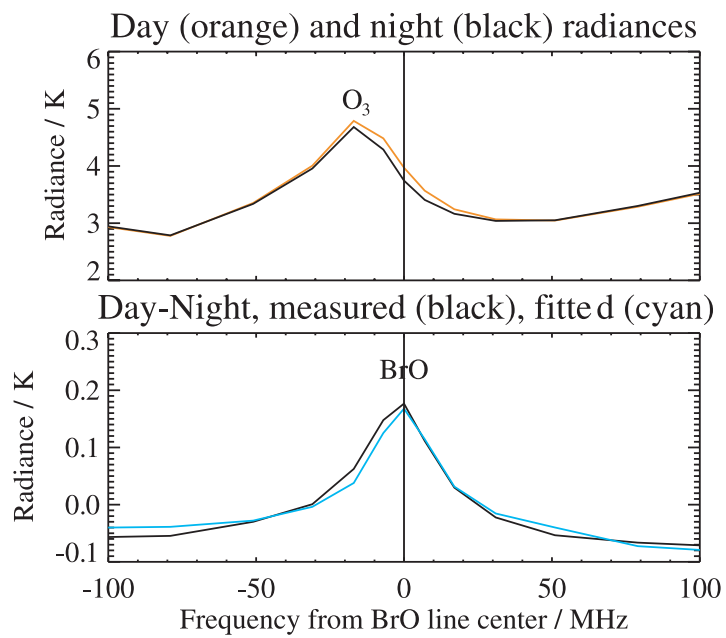

\section{b) $625 \mathrm{GHz}$ (B31F spectral band)}

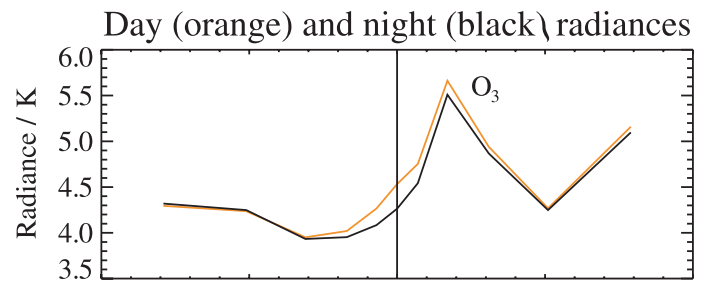

Day-Night, measured (black), fitted (cyan)

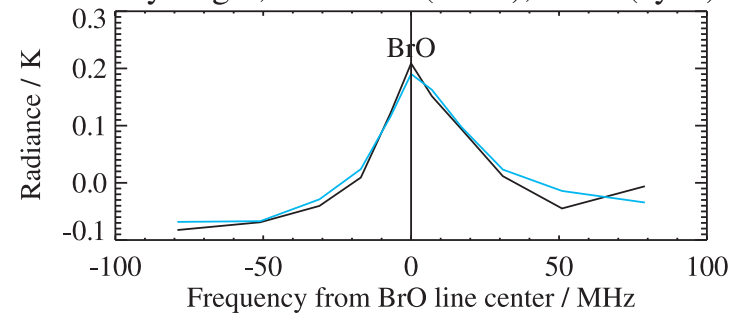

Figure 1. (a) Radiance spectrum of atmospheric emission in the region of the $650 \mathrm{GHz}$ BrO line, MLS spectral band $\mathrm{B} 11 \mathrm{~F}$, as detected by the $\mathrm{R} 4(640 \mathrm{GHz})$ radiometer, at an altitude of $40 \mathrm{~km}$. The spectrum is averaged over 1 year, over latitudes ranging from $55^{\circ} \mathrm{S}$ to $55^{\circ} \mathrm{N}$, and from 10 to $2.2 \mathrm{hPa}$. (b) Same as in Figure 1a except for the $625 \mathrm{GHz}$ BrO line, MLS spectral band B31M. (top) Both the daytime (orange) and nighttime (black) radiances, revealing an overlapping ozone line. (bottom) Difference between the day and night signals (black), revealing the $\mathrm{BrO}$ line. The cyan line is the spectrum predicted from the measured profiles.

global coverage since August 2004. The latest publicly released version 2.2 data are analyzed here. We discuss the precision and accuracy of these data, examine how reasonable they are by comparing with expectations of dependences on latitude and season, and present preliminary comparisons with balloon-based measurements. Because the abundance of $\mathrm{BrO}$ varies strongly with solar zenith angle and with ambient levels of ozone and nitrogen dioxide, we also compare total inorganic bromine $\left(\mathrm{Br}_{\mathrm{y}}\right)$, which is inferred from the $\mathrm{BrO}$ measurements using a photochemical model.

[4] The Aura MLS BrO data have already been used in a scientific study [Livesey et al., 2006a]. However, that study did not use the version of data available publicly at that time, v1.5, because v1.5 BrO was determined to be unsuitable for scientific use. Rather, an interim retrieval version was used, in which a better choice was made in the tradeoff between precision and vertical resolution. Here we evaluate the latest publicly available version of $\mathrm{BrO}$ retrievals, v2.2, and compare them with the previous version, v1.5, as well as with the interim version used by Livesey et al. [2006a].

\section{Description of Aura MLS Observations of BrO}

[5] The Aura satellite orbits the Earth about 14 times per day. The MLS instrument detects thermal emission from the Earth's limb in the millimeter- and submillimeter-wavelength ranges as the field of view is scanned vertically through the atmosphere in the plane of satellite motion. Each vertical scan takes about $24 \mathrm{~s}$ and consists of 120 different forward looking limb radiance measurements, each measurement having an integration time of about $1 / 6$ th of a second. About 3,500 vertical scans are performed each day. At a given latitude, about half of these measurements are of a sunlit atmosphere (during the ascending part of the orbit) and half are of a dark atmosphere (the descending part), except in regions of polar summer or winter, in which case both the ascending and descending measurements are in daylight (polar summer) or darkness (polar winter). The local solar time of the MLS measurements is about 1:45 p.m. for the ascending part of the orbit, and 1:45 a.m. for the descending part, except poleward of about $60^{\circ}$ in latitude. The range of latitudes sampled is from $82^{\circ} \mathrm{S}$ to $82^{\circ} \mathrm{N}$.

[6] $\mathrm{BrO}$ is measured using spectral lines of the ${ }^{81} \mathrm{BrO}$ isotope that correspond to two rotational transitions in the vibrational $(\mathrm{v}=0)$ and electronic $(\mathrm{J}=3 / 2)$ ground state, $\mathrm{N}=$ $47 / 2 \rightarrow \mathrm{N}^{\prime}=49 / 2$, and $\mathrm{N}=49 / 2 \rightarrow \mathrm{N}^{\prime}=51 / 2$. These transitions, at $624.768 \mathrm{GHz}$ and $650.179 \mathrm{GHz}$, respectively, are each split into eight lines by $\Lambda$-doubling and nuclear quadrupole effects, and are spread over a range of about $6 \mathrm{MHz}$. The spectral features are characterized by Drouin et al. [2001], the collision-broadened line widths are reported by Yamada et al. [2003].

[7] The MLS BrO signal strength is only about $0.2 \mathrm{~K}$ brightness temperature, well below the individual measurement noise of about $4 \mathrm{~K}$. Thus significant averaging of individual measurements is required to obtain useful $\mathrm{BrO}$ signal-to-noise. Figure 1a (top) shows a typical spectrum of atmospheric emission in the region of the $650 \mathrm{GHz} \mathrm{BrO}$ line as detected by the MLS R4 (640 GHz) radiometer. This spectrum is averaged over 1 year of measurements, for latitudes ranging from $55^{\circ} \mathrm{S}$ to $55^{\circ} \mathrm{N}$, at a limb/tangent altitude of about $40 \mathrm{~km}$. Both daytime measurements (orange) and nighttime measurements (black) are shown. An interfering ozone line is clearly visible. Taking the difference between the daytime and nighttime signals, shown in Figure 1a (bottom), removes the ozone signal, which does not display a diurnal variation at this altitude. The signal from $\mathrm{BrO}$, which has a strong diurnal variation at this altitude, is thus revealed. Comparison of the measured 
Table 1. Meaning of Bits in the "Status" Field

\begin{tabular}{lll}
\hline Bit & Value $^{\text {a }}$ & \\
\hline 0 & 1 & flag: do not use this profile (see bits $8-9$ for details) \\
1 & 2 & flag: this profile is "suspect" (see bits $4-6$ for details) \\
2 & 4 & unused \\
3 & 8 & unused \\
4 & 16 & information: this profile may have been affected by high altitude clouds \\
5 & 32 & information: this profile may have been affected by low-altitude clouds \\
6 & 64 & information: this profile did not use GEOS-5 temperature a priori data \\
7 & 128 & unused \\
8 & 256 & information: retrieval diverged or too few radiances available for retrieval \\
9 & 512 & information: the task retrieving data for this profile crashed (typically a computer failure) \\
\hline
\end{tabular}

spectrum (black) with that predicted from the retrieved profiles (cyan) shows good agreement. Figure 1b shows similar results for the other $\mathrm{BrO}$ line (at $625 \mathrm{GHz}$ ) that is detected by the same radiometer. Both lines are used for the $\mathrm{BrO}$ retrievals.

[8] The MLS retrieval technique has been described previously [Livesey et al., 2006b]. Profiles are retrieved on a pressure grid of six levels per decade change in pressure ( $\sim 2.5 \mathrm{~km}$ vertical spacing). Retrieved values of $\mathrm{BrO}$ are not constrained to be positive because to obtain a useful signal-to-noise ratio, extensive averaging is required; were the values constrained to be positive, the average would then be biased positive.

[9] Data are stored in HDF-EOS version 5 "swath" format, with each file containing data for a $24 \mathrm{~h}$ period from midnight to midnight universal time. The MLS Version 2.2 data quality document (a preliminary version available at http://mls.jpl.nasa.gov/data) gives more information on the format and content of these data files. Each MLS retrieved data value is stored along with a corresponding precision value that quantifies the impact of MLS radiance measurement noise on the data. As will be discussed below in the section on precision, the value of the precision is made negative if it is worse than $50 \%$ of the value of the a priori precision. Each profile is classified with three fields indicating the quality of the data. The "Quality" field indicates how well the measured radiances can be fit by the retrieval algorithm; higher values indicate a better fit. The "Status" field contains several flags indicating whether there were enough measured radiances, whether clouds might have affected the data, and whether there might be other reasons not to use the data. These Status flags are shown in Table 1. The "Convergence" field indicates how the radiance fit compares with that expected by the retrieval algorithm. Values near 1.0 indicate good agreement. We recommend only using $\mathrm{v} 2.2 \mathrm{BrO}$ data that meet the following criteria: (1) precision value for data point is positive, (2) status field for profile is even, (3) quality for profile is greater than 1.2, and (4) convergence for profile is less than 1.5 .

[10] Version 2.2 (v2.2) is the 2nd public release of MLS data and has been used to process the incoming data stream since March 2007. Reprocessing of the data collected since MLS became operational in August 2004 is also in progress using the v2.2 algorithms. These processing streams have the specific version name v2.21 and include a minor software patch applied to an earlier version v2.20 that corrects the handling of MLS Level 1 radiances flagged as bad data. We refer to both these versions collectively as version 2.2 (v2.2). For this validation effort, only a small subset of days covering late 2004 to early 2007, about 93, has been processed with v2.20, with priority given to days on which there are correlative measurements.

[11] Averaging kernels [Livesey and Read, 2000; Rodgers, 2000; Livesey et al., 2006b] for the v2.2 BrO product are shown in Figure 2. They indicate the vertical resolution of the retrieved product for each pressure level, as well as the dependence of the retrieved product on the a priori. The dashed black line gives the width of each curve at half maximum, a measure of the vertical resolution, which for the pressure range of scientifically useful MLS $\mathrm{BrO}$ ranges from $\sim 5.5 \mathrm{~km}$ at $10 \mathrm{hPa}$ to $\sim 6.0 \mathrm{~km}$ at $3.2 \mathrm{hPa}$. Values are given in Table 2. The solid black line in Figure 2 is the sum of the averaging kernel rows for each pressure surface and indicates the relative amount that the retrieval is based on the MLS measurement as opposed to being based on the a priori; a value near unity indicates that the retrievals are based almost entirely on the MLS measurement. For $\mathrm{BrO}$, the profiles are effectively independent of the a priori for pressures of $0.32 \mathrm{hPa}$ and greater.

\section{Retrieval}

[12] BrO vertical profiles from the first publicly available version, v1.5, are shown in Figure 3 (top). The daily zonal mean profiles (black) of the daytime and nighttime measurements (Figure 3, top left and top middle, respectively) display large oscillations with altitude, as well as strong biases at low altitude. Taking the average (red) of these profiles lessens the range of oscillation, while taking the day/night difference (Figure 3, top right) lessens the magnitude of the bias. A poor choice of tradeoff between precision and vertical resolution led to the oscillations, making v1.5 unsuitable for scientific studies. We then developed a simple interim retrieval version, shown by Figure 3 (middle), in which a better choice was made in the tradeoff between precision and vertical resolution. For this interim version, daily zonal mean radiances were calculated, from which vertical profiles of $\mathrm{BrO}$ were then retrieved [Livesey et al., 2006a]. The most recent version, $\mathrm{v} 2.2$, is shown in Figure 3 (bottom). It differs from v1.5 in that smoother profiles are obtained at the expense of decreased vertical resolution. Moreover, new spectroscopy is used for the stronger ozone lines (located in a different spectral region than the $\mathrm{BrO}$ emission) (B. J. Drouin and R. R. Gamache, manuscript in preparation, 2007), which significantly reduces v1.5 biases that had been empirically 


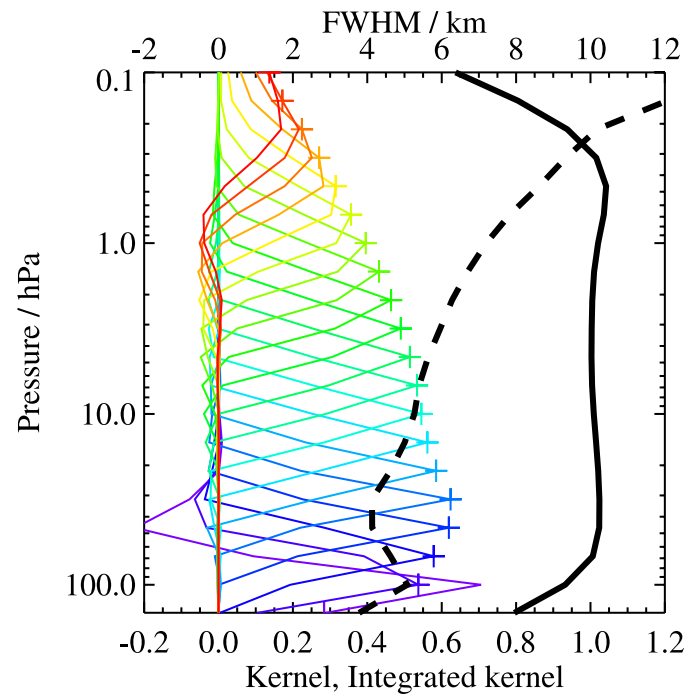

Figure 2. Vertical averaging kernels (integrated in the horizontal dimension for five along-track profiles) for MLS $\mathrm{v} 2.2 \mathrm{BrO}$ at a latitude of $35^{\circ} \mathrm{N}$. Variation in the averaging kernels is sufficiently small that these are representative of all profiles. Each colored curve shows the averaging kernel for a particular MLS pressure surface (denoted by a plus sign in the corresponding color) and indicates the region of the atmosphere from which information is contributing to the measurements on that individual retrieval surface. The full-width at half maximum (FWHM) of each curve along the pressure axis is a measure of the vertical resolution of the retrieved profile for that pressure surface. That width, as measured in $\mathrm{km}$ (top axis), is shown by the dashed black curve. The solid black curve shows the sum of the averaging kernel columns for each of the pressure surfaces (i.e., is the integrated area under each two-dimensional kernel, both horizontal and vertical) and is an indication of how much of the retrieved product is based on the a priori. Values near unity imply that the majority of information for that MLS data point has come from the measurements, while values near zero imply the majority has come from the a priori.

ascribed to ozone. Compared to the old HITRAN spectroscopic constants, the new line widths are, on average, $8 \%$ more narrow at $296 \mathrm{~K}$ and show more variability in the temperature exponents. Changes in the line strengths and positions are negligible (less than a tenth of a percent). Figure 3 shows that for the pressure range over which MLS measurements of $\mathrm{BrO}$ are useful, from 10 to $3.2 \mathrm{hPa}$ (as will be justified below), the average nighttime v2.2 $\mathrm{BrO}$ (red) shows larger positive biases than does the average nighttime interim version $\mathrm{BrO}$, while the day/night difference is comparable, with $\mathrm{v} 2.2$ showing about 3 ppt more $\mathrm{BrO}$ than the interim version. Table 3 summarizes the three retrieval versions.

\section{Precision}

[13] The expected precision in each retrieved profile is calculated from radiance noise and stored in the data files with each retrieval value. As mentioned earlier, as a data quality flag, the value of the precision is made negative if it is worse than $50 \%$ of the value of the a priori precision. Figure 4 compares the expected precision (thick line) of one measurement of $\mathrm{BrO}$ with the measured precision (circles) based on the scatter in the retrieved profiles, for both v1.5 and v2.2 retrievals. Also shown is the precision for daily, monthly, and yearly $10^{\circ}$ zonal averages. The precision is seen to have improved in v2.2, at the expense of vertical resolution. As shown in Figure 4, a monthly zonal mean over a $10^{\circ}$ latitude bin (about 3,000 individual profiles) results in an estimated precision of about \pm 4 ppt (about $20 \%$ of a typical daily signal) over a pressure range from 10 to $3.2 \mathrm{hPa}$.

[14] Figure 5 shows a histogram of the distribution of daytime (shaded region) and nighttime (red line) $\mathrm{BrO}$ measurements for four different pressure surfaces over a latitude range from $55^{\circ} \mathrm{S}$ to $55^{\circ} \mathrm{N}$ for the days reprocessed in v2.2 to date. Also shown is a Gaussian fit (black line) to the daytime measurements, which are seen to have the Gaussian distribution expected from noise and a width that closely matches the estimated precision. The diurnal variation in $\mathrm{BrO}$ is discernible for the lower altitudes.

\section{Accuracy}

[15] We now address quantification of the various sources of systematic uncertainty in the MLS BrO product. Systematic errors (which are reproducible but cannot be lessened by averaging) can be introduced into the retrieved product by errors in instrument calibration (e.g., through radiometric calibration and field-of-view characterization), through spectroscopic uncertainties or approximations, and by approximations in the retrieval formulation and implementation. A comprehensive assessment of systematic errors and their effect on all the MLS products is given by Read et

Table 2. Summary of Aura MLS BrO Product ${ }^{\mathrm{a}}$

\begin{tabular}{lccccc}
\hline Region, hPa & $\begin{array}{c}\text { Vertical } \\
\text { Resolution, } \mathrm{km}\end{array}$ & Precision, ${ }^{\mathrm{b}}$ ppt & $\begin{array}{c}\text { Bias } \\
\text { Uncertainty, }{ }^{\mathrm{c}} \mathrm{ppt}\end{array}$ & $\begin{array}{c}\text { Scaling } \\
\text { Uncertainty, }{ }^{\mathrm{c}} \%\end{array}$ & Comments \\
\hline 2.2 and less & - & - & - & - & unsuitable for scientific use \\
3.2 & 6 & \pm 5 & \pm 6 & \pm 20 & need to account for nonnegligible nighttime BrO \\
4.6 & 5.5 & \pm 4 & \pm 9 & \pm 20 & \\
6.8 & 5.5 & \pm 4 & \pm 20 & \pm 20 & \\
10 & 5.5 & - & - & - & unsuitable for scientific use \\
$150-15$ & - & - & - & - & not retrieved \\
$1000-215$ & - & -4 & & & \\
\hline
\end{tabular}

${ }^{a}$ Because of large biases in the data, the daytime and nighttime $\mathrm{BrO}$ data at all pressure levels are unsuitable for scientific use. Rather, day/night differences must be used. Note that day/night differences are not useful for polar winter and summer, where $\mathrm{BrO}$ does not undergo a diurnal variation.

${ }^{\mathrm{b}}$ Precision is for a $10^{\circ}$ monthly zonal mean profile.

${ }^{\mathrm{c}}$ Accuracy is based on the systematic error tests. 

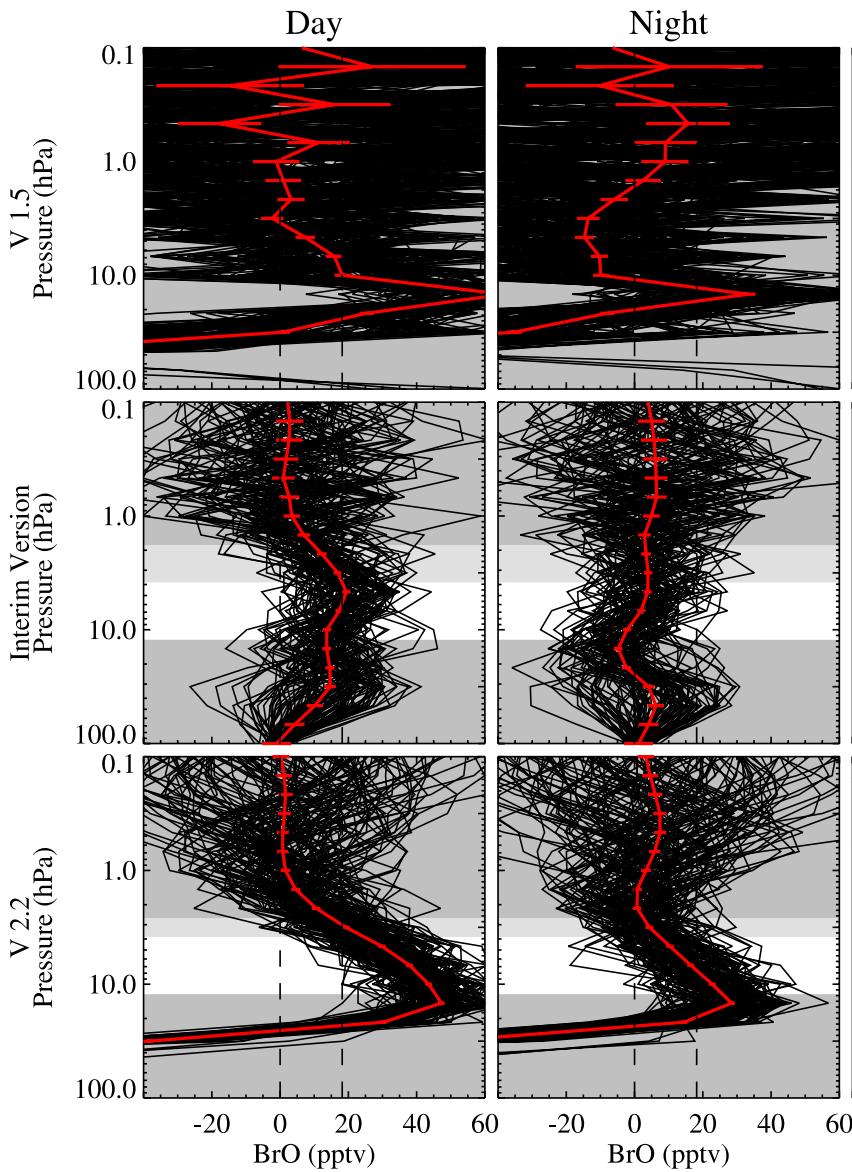

\section{Difference}
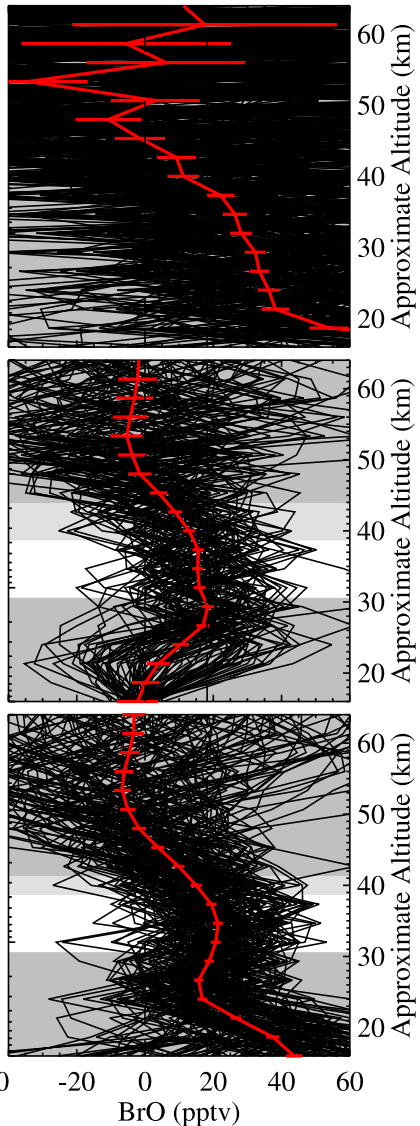

Figure 3. Vertical profiles for three retrieval approaches for daytime, nighttime, and day/night difference. Profiles are averaged over the subset of days (149) retrieved to date with v2.2 and over latitudes from $35^{\circ} \mathrm{N}$ to $45^{\circ} \mathrm{N}$. (top) Version 1.5 , (middle) the interim version, and (bottom) version 2.2. Black profiles are daily zonal means; red is the average. Error bars show precision only. (We note that the average for the interim version corresponds to the version 2.2 subset of retrieved days occurring before 5 March 2006; after this date, data for the interim version were not processed.) To make comparison easier, a dashed vertical line is drawn at $18.2 \mathrm{ppt}$, the value of the interim version average $\mathrm{BrO}$ at $10 \mathrm{hPa}$. Regions shaded dark gray indicate where MLS BrO has been determined to be unsuitable for scientific use. Regions shaded light gray indicate where nighttime $\mathrm{BrO}$ needs to be taken into account in the day/ night difference for that difference to be a good measure of daytime BrO.

Table 3. MLS BrO Retrieval Versions

\begin{tabular}{|c|c|c|c|}
\hline & $1.5^{\mathrm{a}}$ & Interim & 2.2 \\
\hline Region, ${ }^{\mathrm{b}, \mathrm{c}} \mathrm{hPa}$ & 10 to $1^{\mathrm{a}}$ & 10 to 2.2 & 10 to 3.2 \\
\hline Vertical resolution, $\mathrm{km}$ & $2.5^{\mathrm{a}}$ & 6 & 5.5 to $6^{\mathrm{d}}$ \\
\hline Precision, ${ }^{\mathrm{d}, \mathrm{e}} \mathrm{ppt}$ & $\pm 20^{\mathrm{a}}$ & \pm 3 & \pm 4 to $5^{\mathrm{d}}$ \\
\hline Bias uncertainty, ppt & \pm 3 to $10^{\mathrm{a}}$ & - & \pm 6 to $30^{\mathrm{d}}$ \\
\hline Scaling uncertainty, \% & - & \pm 30 & \pm 20 \\
\hline Comments & $\begin{array}{l}\text { poor choice of tradeoff between } \\
\text { precision and vertical resolution }\end{array}$ & zonal averages of radiances & $\begin{array}{l}\text { better choice of } \\
\text { tradeoff between precision } \\
\text { and vertical resolution; new } \\
\text { ozone spectroscopic constants }\end{array}$ \\
\hline
\end{tabular}

\footnotetext{
${ }^{\mathrm{a}}$ Version 1.5 is unsuitable for scientific use at all pressures.

${ }^{b}$ Pressure range over which the day/night difference is scientifically useful. Because of large biases in the data, the daytime and nighttime BrO data at all pressure levels are unsuitable for scientific use; rather, day/night difference must be used. Note that day/night differences are not useful for polar summer and winter, where $\mathrm{BrO}$ does not undergo a diurnal variation.

${ }^{c}$ For pressures $\leq 3.2$, the day/night difference is not a good measure of daytime $\mathrm{BrO}$.

${ }^{\mathrm{d}}$ Depends on pressure range. See Table 2 for more details.

${ }^{\mathrm{e}}$ Precision is for a $10^{\circ}$ monthly zonal mean profile.
} 

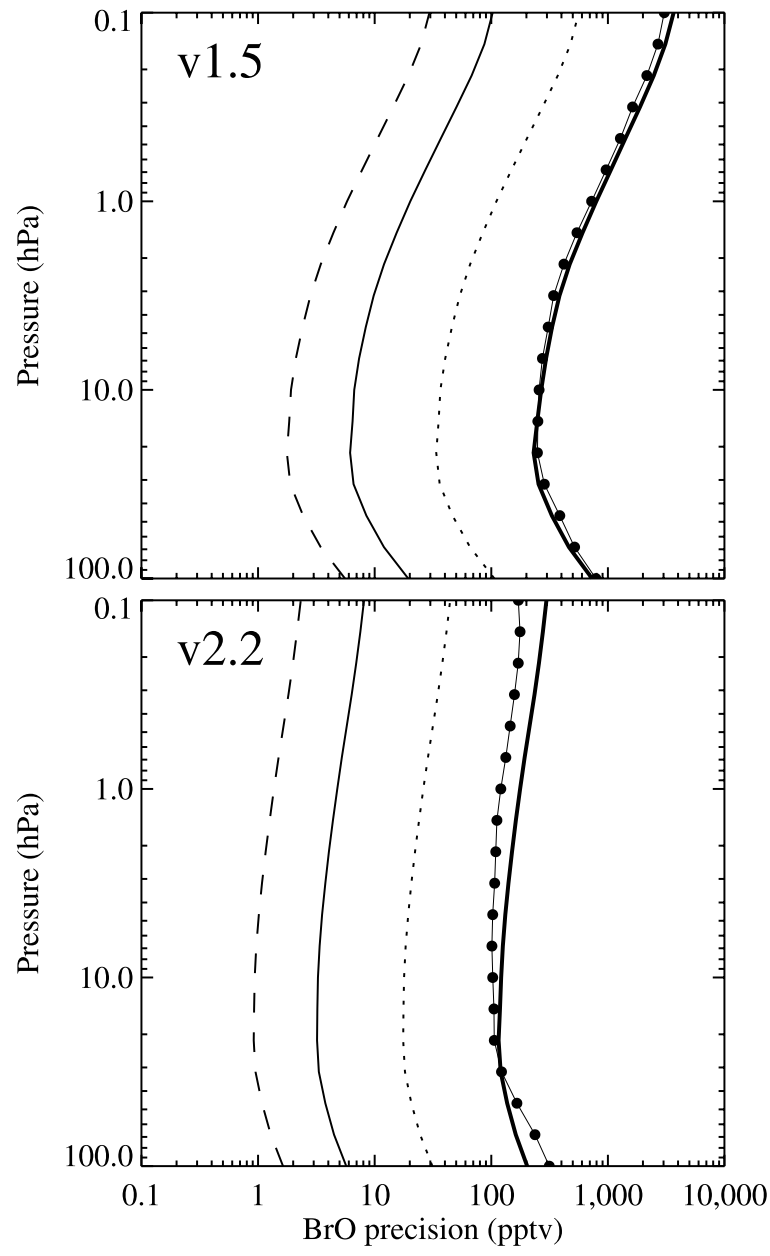

Figure 4. Comparison of the measured precision (circles) with that expected from the retrieval (thick solid line), for a single profile, for (top) v1.5 and (bottom) v2.2. The measured precision on a single profile was determined from the scatter in nighttime profiles retrieved over a single day within a $10^{\circ}$ latitude bin. Also shown is the expected precision for the day/night difference of $10^{\circ}$ zonal mean profiles averaged over a day (dotted line), a month (thin solid line) and a year (dashed line).

al. [2007, Appendix A]. In this section we summarize the results of this assessment relevant for the $\mathrm{BrO}$ product.

[16] The effect of each identified source of systematic error on MLS measurements of radiance has been quantified and modeled. These quantified effects correspond to either $2 \sigma$ estimates of uncertainties in each MLS product, or an estimate of the maximum reasonable uncertainty based on instrument knowledge and/or design requirements. For each source of systematic error, we have used one of the following two methods to quantify the effect on the MLS retrieved products.

[17] In the first method, sets of modeled errors corresponding to the possible magnitude of each uncertainty have been applied to simulated MLS cloud-free radiances, based on a model atmosphere, for a whole day of MLS observations. These sets of perturbed radiances have then been run through the routine MLS data processing algorithms, and the differences between these runs and the results of an "unperturbed" run have been used as a measure of the systematic uncertainty in each case. Although the term "systematic uncertainty" typically refers to an unknown additive bias or scaling factor, many of the sources of systematic uncertainty in the MLS measurements give rise to additional "scatter" in the products. For example, although an error in the ozone spectroscopy directly causes a bias on the ozone retrieval, it also has a secondary effect on the retrieval of other species with overlapping lines. The difference between the retrieved product in the unperturbed run and the original "truth" model atmosphere is taken as a measure of uncertainties due to retrieval formulation and numerics. The concentration in the unperturbed case is plotted against the concentration in the perturbed case. A linear regression produces an intercept and a slope. The intercept is a measure of errors that are independent of the concentration (additive bias), while the deviation of the slope from unity is a measure of errors that are proportional to the concentration (multiplicative error). When day/night differences are taken, the additive bias errors should cancel, while the multiplicative errors remain.

[18] In the second method, the potential impact of some remaining (typically small) systematic uncertainties has been quantified through calculations based on simplified models of the MLS measurement system [Read et al., 2007]. These calculations provide estimates of possible multiplicative error.

[19] The first panel in Figure 6 shows an estimate of the potential magnitude of the additive biases introduced into the v2.2 BrO product by each of the sources of error listed in Figure 6. The first panel in Figure 7 zooms in on the pressure region over which $\mathrm{MLS} \mathrm{BrO}$ measurements are useful. These values should be considered as $2 \sigma$ estimates of their probable magnitude. The second panel in Figures 6

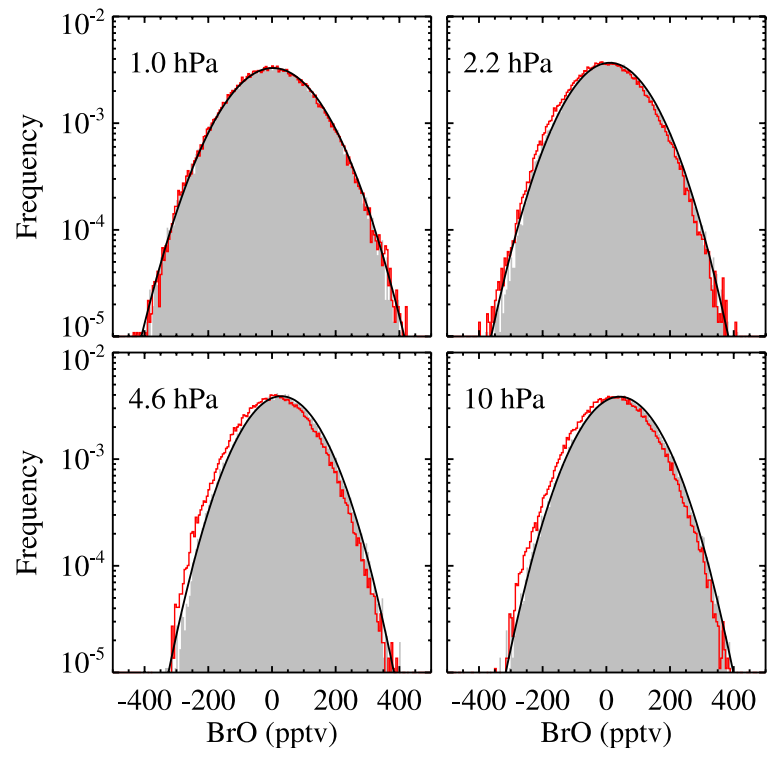

Figure 5. Histogram showing the distribution of daytime (shaded region) and nighttime (red curve) MLS BrO measurements at four different pressure surfaces for a latitude range from $55^{\circ} \mathrm{S}$ to $55^{\circ} \mathrm{N}$ for all the v2.2 data processed to date. The black line shows a Gaussian fit to the daytime data. 


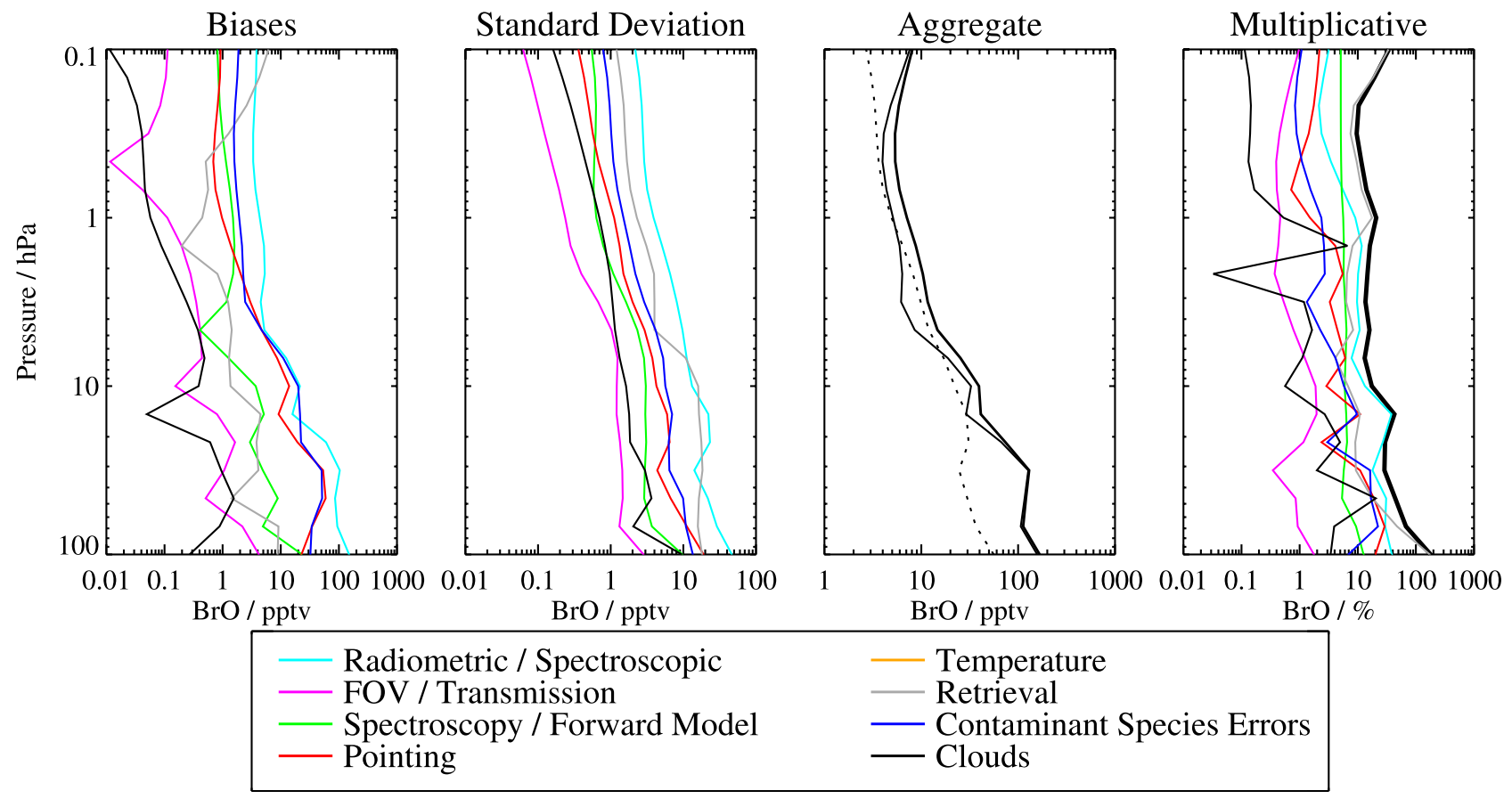

Figure 6. Estimated accuracy in v2.2 BrO measurements. The first panel shows the estimated potential magnitude of the systematic additive error, or bias, introduced into $\mathrm{BrO}$ by each of eight sources, while the second panel shows the additional scatter (see text) introduced into the retrieved values by each of the sources of uncertainty. The third panel shows the root sum squares (RSS) of all the biases (thin solid); the RSS of all the additional scatters, or standard deviations (dotted); and the RSS of the two (thick solid). The fourth panel shows the estimated potential multiplicative bias.

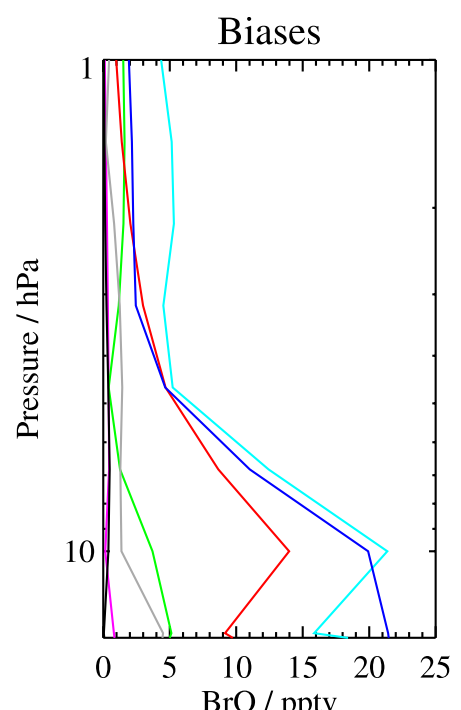

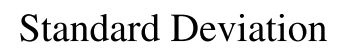

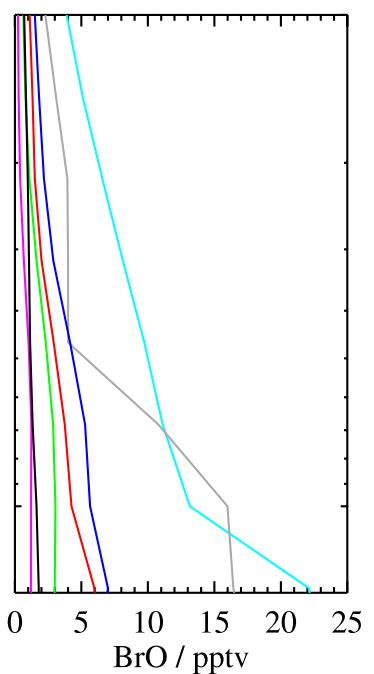

/ pptv
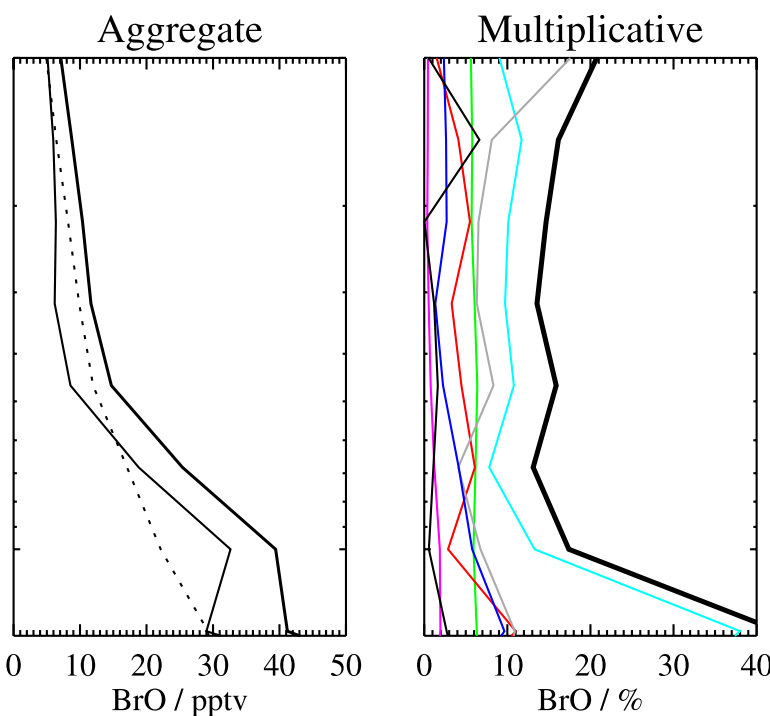

Temperature

- Retrieval

- Contaminant Species Errors

- Clouds

Figure 7. Same as Figure 6 except that it is a blowup of the pressure region over which MLS BrO is scientifically useful. Note that the $x$ axis is linear. 
and 7 shows additional scatter in the additive bias introduced by each of these sources.

[20] The dominant source of additive systematic error in the MLS BrO product is uncertainty in the MLS radiometric and spectroscopic calibration (cyan), and is mainly due to the spectral signature introduced in MLS radiances by departures from a linear response within the signal chain that are not accounted for in the calibration. This uncertainty alone can cause a potential additive bias in $\mathrm{BrO}$ of up to about $\pm 20 \mathrm{ppt}$ at $10 \mathrm{hPa}$, and up to about $\pm 100 \mathrm{ppt}$ at $31.6 \mathrm{hPa}$. A second major contributor to systematic errors in the $\mathrm{BrO}$ signal is uncertainty in overlapping signals from other species (blue), mainly ozone, as seen in Figure 1, though nitric acid also contributes. This uncertainty alone can cause a potential additive bias of up to $\pm 20 \mathrm{ppt}$ at $10 \mathrm{hPa}$, and up to $\pm 50 \mathrm{ppt}$ at $31.6 \mathrm{hPa}$. A third major contributor to additive bias is pointing (red), which is caused by the impact of errors in the assumed width of the oxygen line used in the MLS pointing retrieval, uncertainty in the field of view pointing offsets between the $640 \mathrm{GHz}$ and $240 \mathrm{GHz}$ radiometers, and the uncertainty in the field of view pointing offsets between the two $118 \mathrm{GHz}$ radiometers and the $240 \mathrm{GHz}$ radiometer. This uncertainty alone contributes up to about \pm 15 ppt at $10 \mathrm{hPa}$, and up to $\pm 50 \mathrm{ppt}$ at $31.6 \mathrm{hPa}$.

[21] The aggregate additive bias uncertainty in MLS BrO measurements, shown by the thin line in the third panel of Figures 6 and 7 , can be as high as about \pm 30 ppt ( $\sim 400 \%$ of the expected $\mathrm{BrO}$ signal) at $10 \mathrm{hPa}$, decreasing to about $\pm 6 \mathrm{ppt}(50 \%)$ at $3.2 \mathrm{hPa}$. Because averages over large numbers of profiles are needed to obtain useful precision for MLS BrO, the additional scatter (dotted line) introduced into the data from these sources of uncertainty will become negligible, and thus the aggregate (thick line) of the biases and scatter will average down to just the biases (thin line).

[22] The fourth panels in Figures 6 and 7 show the multiplicative uncertainty (the accuracy as a percent of the signal, as opposed to an additive bias) introduced into the MLS BrO measurements from the sources of error listed above. For the pressure range over which MLS BrO measurements are useful, 10 to $3.2 \mathrm{hPa}$, this scaling uncertainty is up to about $\pm 20 \%$ of the signal.

[23] We can dramatically reduce the effects of the additive bias in the $\mathrm{BrO}$ signal by taking advantage of the diurnal variation of $\mathrm{BrO}$ and subtracting the nighttime signal from the daytime signal. For pressures of $4.6 \mathrm{hPa}$ and greater, our calculations show that the nighttime $\mathrm{BrO}$ is expected to be negligible, and therefore this difference is a measure of the daytime BrO. For lower pressures, the subtraction can still be done; however, for the difference to be a good measure of the daytime $\mathrm{BrO}$, the nonnegligible nighttime $\mathrm{BrO}$ signal will need to be taken into account (perhaps with the aid of a photochemical model). While taking day/night differences minimizes the additive bias, which we treat as negligible, it does not affect the multiplicative uncertainty factor, which remains at up to about $\pm 20 \%$.

[24] The uncertainty in the MLS BrO data due to systematic errors is summarized in Table 2 . We conclude that it is necessary to take day/night differences in the measurements of BrO. Even so, because of the extremely large biases at $15 \mathrm{hPa}$ and larger pressures, $(+30 \mathrm{ppt}$ at $15 \mathrm{hPa}$,
$-40 \mathrm{ppt}$ at $26 \mathrm{hPa}$, and becoming even more negative for higher pressures), we conclude that MLS BrO is not useful for scientific studies in this region. For pressures ranging from 10 to $4.6 \mathrm{hPa}$, and with sufficient averaging, the error analysis indicates that the MLS BrO abundance uncertainty is about $\pm 20 \%$. For $3.2 \mathrm{hPa}$, the day/night difference can be known to within an uncertainty of $20 \%$, but for this difference to be a good estimate of daytime $\mathrm{BrO}$, one will need to compensate for the nonnegligible nighttime $\mathrm{BrO}$. We note that this method of taking day/night differences is not applicable for polar summer and winter, where $\mathrm{BrO}$ is constant throughout the day and night.

\section{Comparison With Expectations}

[25] The SLIMCAT chemistry-transport model [Chipperfield, 1999] was run in "near-real time" and driven by U.K. Met Office analysis wind and temperature fields. Model results were sampled at the same locations and times as MLS profile observations. JPL 2002 kinetics [Sander et al., 2003] were used, with the addition of the reaction $\mathrm{BrONO}_{2}+\mathrm{O} \rightarrow \mathrm{BrO}+$ $\mathrm{NO}_{3}$ [Soller et al., 2001], which is included in the JPL 2006 kinetics compendium [Sander et al., 2006]. The model was initialized with 16 ppt $\mathrm{CH}_{3} \mathrm{Br}$ (long-lived source for inorganic bromine) plus 6 ppt of $\mathrm{Br}_{\mathrm{y}}$ (in the form of $\mathrm{BrO}$ and $\mathrm{BrONO}_{2}$ ) to represent the effect of short-lived sources at the $326 \mathrm{~K}$ model boundary; model results show that all of the bromine is in the form of inorganic bromine $\left(\mathrm{Br}_{\mathrm{y}}\right)$ for pressures less than $30 \mathrm{hPa}$.

[26] Figure 8 shows seasonal zonal means of ascending (Figure 8a), descending (Figure 8b), and the day/night difference (Figure 8c) MLS v2.2 $\mathrm{BrO}$ as a function of pressure and latitude. The precision on the day/night differences depends on the number of measurement days in that season: about \pm 6 ppt for SON 2004, DJF 2004/5, and MAM 2005; and about \pm 10 ppt for JJA 2005. These plots can be compared with corresponding plots of SLIMCAT BrO, shown in Figure 9. The MLS BrO day/night difference shows the expected behavior with season and latitude. At midlatitudes and tropics, MLS BrO displays a diurnal variation, with more $\mathrm{BrO}$ during the day than at night. In the polar summer and winter regions, with constant daytime and nighttime, respectively, the MLS day/night difference is close to zero.

[27] We take a more quantitative look at the comparison of MLS BrO day/night differences and SLIMCAT values in the midlatitude and tropics for the four seasons by using a scatterplot, shown in Figure 10. As in Figure 9, the MLS data points represent seasonal zonal means averaged over $10^{\circ}$ latitude bins. We see that although the MLS data points exhibit significant scatter, they are distributed about the SLIMCAT values. Implications for total inorganic bromine $\left(\mathrm{Br}_{\mathrm{y}}\right)$ are discussed in section 8 .

[28] Figure 11 shows vertical profiles of seasonal averages of MLS v2.2 BrO during polar summer in the northern hemisphere (NH) (Figure 11, top) and southern hemisphere (SH) (Figure 11, bottom), for ascending (daytime) measurements, descending (also daytime) measurements, and the ascending/descending difference. These are compared with SLIMCAT model profiles, similarly averaged. The large biases in the MLS BrO data (for both ascending and descending measurements) are evident. The origin of these 

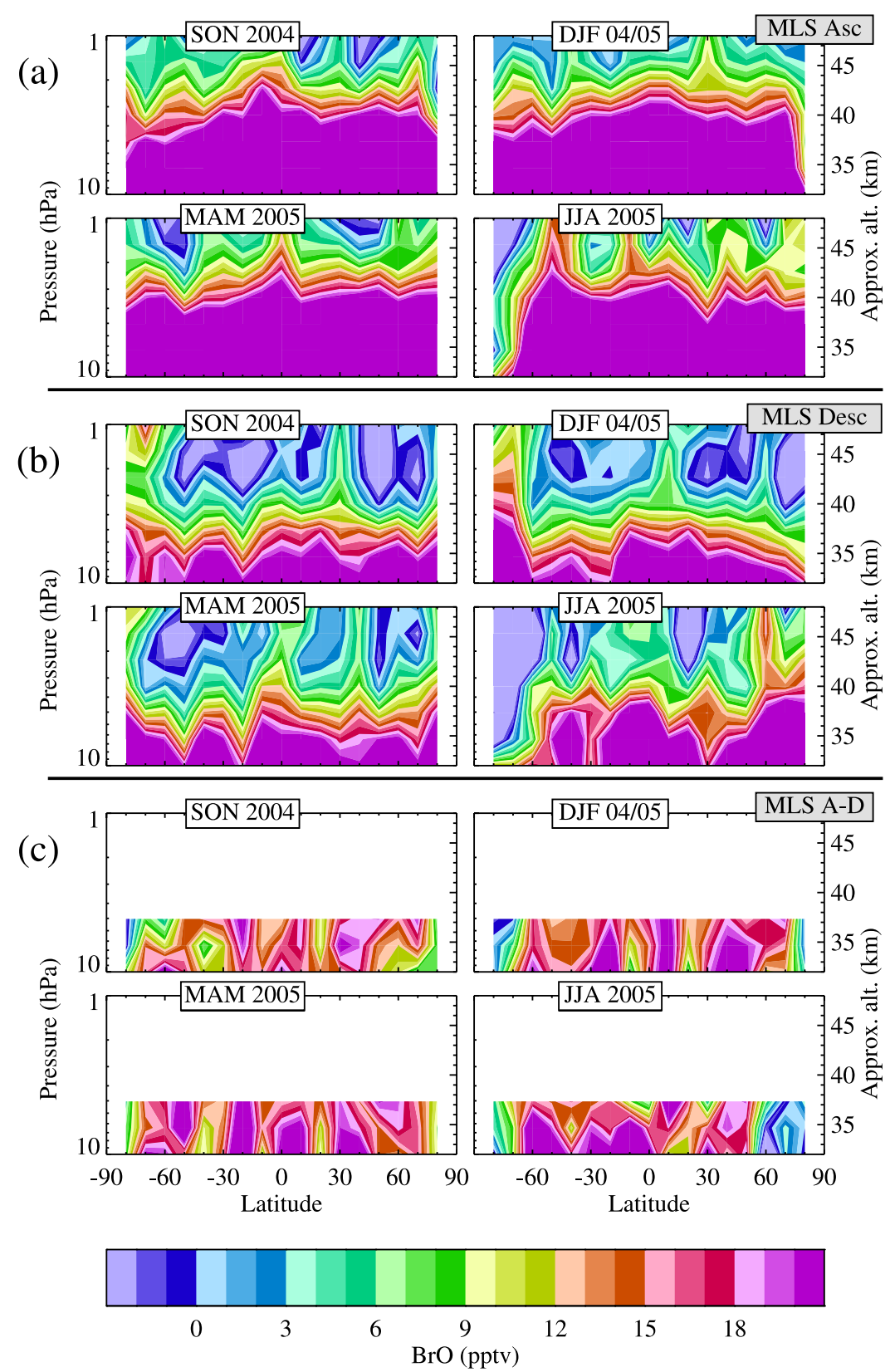

Figure 8. Seasonal zonal means of MLS BrO observations for (a) ascending (mainly daytime) and (b) descending (mainly nighttime) phases of the orbits. (c) To alleviate biases in the lower-altitude regions, the ascending/descending difference can be used as a measure of daytime $\mathrm{BrO}$, so long as the expected nighttime abundance of $\mathrm{BrO}$ is negligible, which is the case for MLS difference data on the $4.6 \mathrm{hPa}$ and greater pressure surfaces shown here.

is discussed in section 5 on accuracy. Over the pressure range 10 to $3.2 \mathrm{hPa}$, the MLS $\mathrm{BrO}$ difference profiles are zero within the expected uncertainty (i.e., taking the difference removes the biases apparent in the ascending and descending data). However, for lower pressures, a large deviation from zero is seen for the SH (Figure 11, bottom) difference profile, by as much as $10 \pm 5 \mathrm{ppt}$ at $1.5 \mathrm{hPa}$. Because this difference is not behaving as expected for these lower pressures, we define $3.2 \mathrm{hPa}$ to be the lowest pressure for scientific use, though this may be overly cautious.
[29] Figure 12 shows the same as Figure 11 except for polar winter regions. For the NH polar winter (Figure 12, top), the SLIMCAT model results show that the difference is not expected to be zero, because over the days included in the seasonal average, there is some sunlight during the ascending part of the orbit. In this case, the MLS day/night difference also differs from zero.

[30] Figure 13 shows a time series of daily zonal mean MLS BrO over the whole mission for both v1.5 (black) and v2.2 (red) for descending (nighttime) measurements (Figure 13, top) and day/night differences (Figure 13, bottom). In Figure 13 (top), a discontinuity is seen in the 

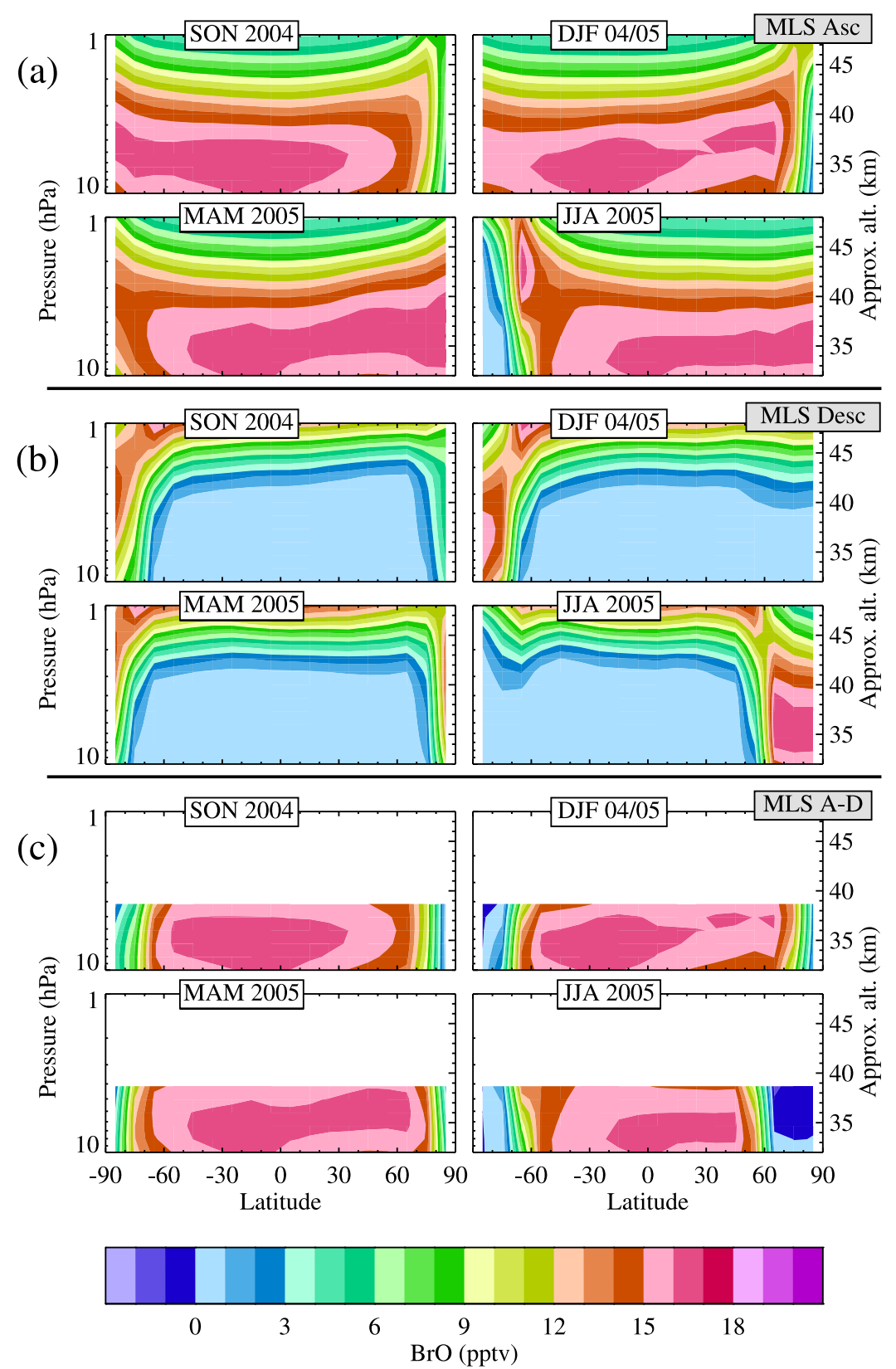

Figure 9. Same as Figure 8 except for SLIMCAT model estimates of BrO.

v1.5 descending (nighttime) data at about March 2006, which was caused by a change in the spectrometers when MLS band 13 [Waters et al., 2006] was switched off to conserve measurement capability. While this band is not used to detect the $\mathrm{BrO}$ signal, it is used in the retrieval of other species and thus can affect the background signal. It can be seen that this discontinuity is removed by taking day/ night differences, as shown in Figure 13 (bottom). As version 2.2 was designed subsequent to the band being switched off, it is reassuring to see that no corresponding discontinuity is seen in the v2.2 nighttime data.

\section{Comparison With Other Measurements}

[31] We now compare vertical profiles of MLS BrO with measurements by balloon-borne instruments. While better comparisons would be obtained by taking monthly zonal means of MLS BrO profiles about the dates and latitudes of each flight, the required v2.2 data are not yet available. Thus, to achieve reasonable precision, we take an average of all the days (149) of MLS v2.2 reprocessed to date, over a zonal mean from $55^{\circ} \mathrm{S}$ to $55^{\circ} \mathrm{N}$. This latitude range is chosen to ensure that measured $\mathrm{BrO}$ undergoes a diurnal variation. This average samples all seasons and a large range of solar zenith angles, $26^{\circ}$ to $73^{\circ}$.

[32] Because $\mathrm{BrO}$ abundances vary strongly with solar zenith angle, as well as with local abundances of $\mathrm{O}_{3}$ and $\mathrm{NO}_{2}$, we also compare vertical profiles of total inorganic bromine $\left(\mathrm{Br}_{\mathrm{y}}\right)$, which are not as sensitive to local conditions. Values of $\mathrm{Br}_{\mathrm{y}}$ are inferred from the $\mathrm{BrO}$ measurements using a photochemical model [Osterman et al., 1997]. Importantly, since all the organic bromine is 

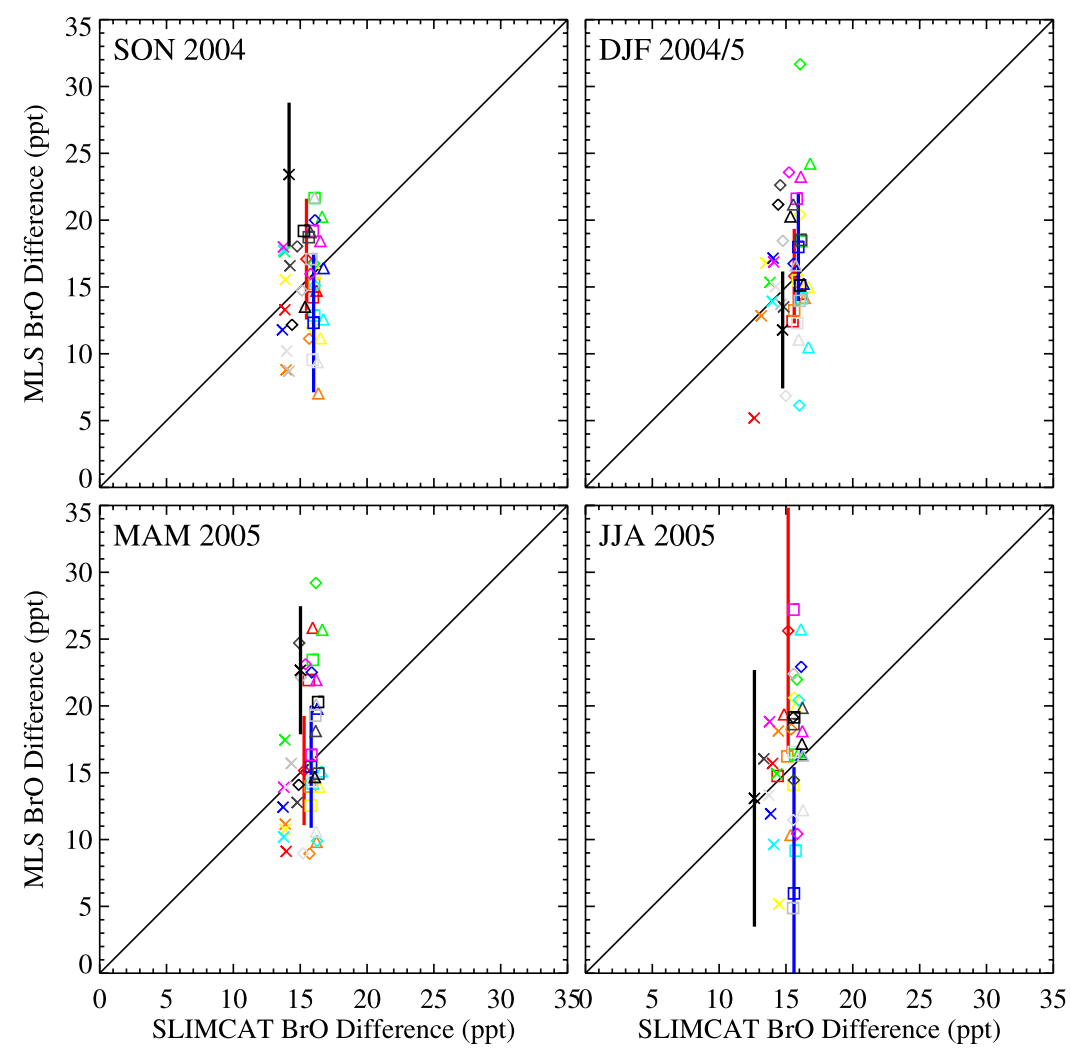

0

Figure 10. Scatterplot of midlatitude and tropics MLS day/night difference BrO data versus SLIMCAT. Data points represent seasonal $10^{\circ}$ zonal means, as in Figure 9c, for pressures ranging from 10 to $3.2 \mathrm{hPa}$. Different symbols represent the four pressure surfaces (diamond, $10 \mathrm{hPa}$; triangle, $6.4 \mathrm{hPa}$; square, $4.6 \mathrm{hPa}$; cross, $3.2 \mathrm{hPa}$ ), and different colors represent the 11 latitude bins (red, $50^{\circ} \mathrm{S}$; orange, $40^{\circ} \mathrm{S}$; yellow, $30^{\circ} \mathrm{S}$; green, $20^{\circ} \mathrm{S}$; cyan, $10^{\circ} \mathrm{S}$; blue, $0^{\circ}$; magenta, $10^{\circ} \mathrm{N}$; light gray, $20^{\circ} \mathrm{N}$; gray, $30^{\circ} \mathrm{N}$; dark gray, $40^{\circ} \mathrm{N}$; black, $\left.50^{\circ} \mathrm{N}\right)$. The MLS error bars show the scatter $( \pm 1 \sigma$ standard deviation) of the daily zonal means about the seasonal average for three representative latitudes and pressures.

expected to have been photochemically converted to inorganic bromine at altitudes above $25 \mathrm{~km}$, even for cases where the balloon measurements do not overlap the MLS measurements, the $\mathrm{Br}_{\mathrm{y}}$ comparison is expected to be meaningful. However, because stratospheric bromine loading has changed over time [Montzka et al., 2003; WMO, 2003; Dorf et al., 2006b], $\mathrm{Br}_{\mathrm{y}}$ depends on the age of air, which varies with both altitude and latitude. Thus, to account for the age of air differences in the measurements, we also compare them on a plot of $\mathrm{Br}_{\mathrm{y}}$ vs. $\mathrm{N}_{2} \mathrm{O}$.

[33] We infer $\mathrm{Br}_{\mathrm{y}}$ vertical profiles from the measured $\mathrm{BrO}$ profiles using a Photochemical Steady State (PSS) box model. The PSS model is constrained to measurements of $\mathrm{BrO}, \mathrm{O}_{3}$, and $\mathrm{NO}_{2}$, as described by Sioris et al. [2006] and Livesey et al. [2006a]. Since MLS does not measure $\mathrm{NO}_{2}$, we estimate it using MLS measurements of $\mathrm{N}_{2} \mathrm{O}$ to specify $\mathrm{NO}_{\mathrm{y}}$ (based upon well-established tracer relations) and PSS estimates of the $\mathrm{NO}_{2} / \mathrm{NO}_{\mathrm{y}}$ ratio. We use JPL 2002 kinetics [Sander et al., 2003] with the addition of the reactions $\mathrm{BrONO}_{2}+\mathrm{O} \rightarrow \mathrm{BrO}+\mathrm{NO}_{3}$ [Soller et al., 2001], and $\mathrm{BrO}+$ $\mathrm{OH} \rightarrow \mathrm{Br}+\mathrm{HO}_{2}$ [Bedjanian et al., 2001], both of which are included in JPL 2006 [Sander et al., 2006]. In addition, we update all reaction rate constants for reactions involving bromine to JPL 06 values. Preliminary runs with JPL 2006 kinetics show that for the bromine family, model results using JPL 2002 kinetics with these changes are in agreement with those using JPL 2006 kinetics. The uncertainty in $\mathrm{Br}_{\mathrm{y}}$ was determined by performing a sensitivity analysis with the PSS model, individually varying the abundances of $\mathrm{BrO}$ and $\mathrm{NO}_{2}$, as well as the rate constants for production and loss of $\mathrm{BrO}$, and then adding the resulting changes in $\mathrm{Br}_{\mathrm{y}}$ in quadrature [Sioris et al., 2006].

[34] Vertical profiles of $\mathrm{BrO}$ obtained by the satelliteborne instrument SCIAMACHY (Scanning Imaging Absorption Spectrometer for Atmospheric Cartography) are available as well [Sinnhuber et al., 2005; Sheode et al., 2006; Sioris et al., 2006]. However, the two sets of SCIAMACHY BrO data, obtained using two different retrieval methods, do not agree with each other [WMO, 2007, section 2.5.2.1]. In section 7.5 we present a comparison of $\mathrm{Br}_{\mathrm{y}}$ inferred from MLS measurements of $\mathrm{BrO}$ to the two sets of published values of $\mathrm{Br}_{\mathrm{y}}$ that have been inferred from SCIAMACHY BrO retrievals.

\subsection{Comparison With DOAS BrO}

[35] We first consider measurements of stratospheric $\mathrm{BrO}$ obtained by the remote-sensing, balloon-borne, Differential 


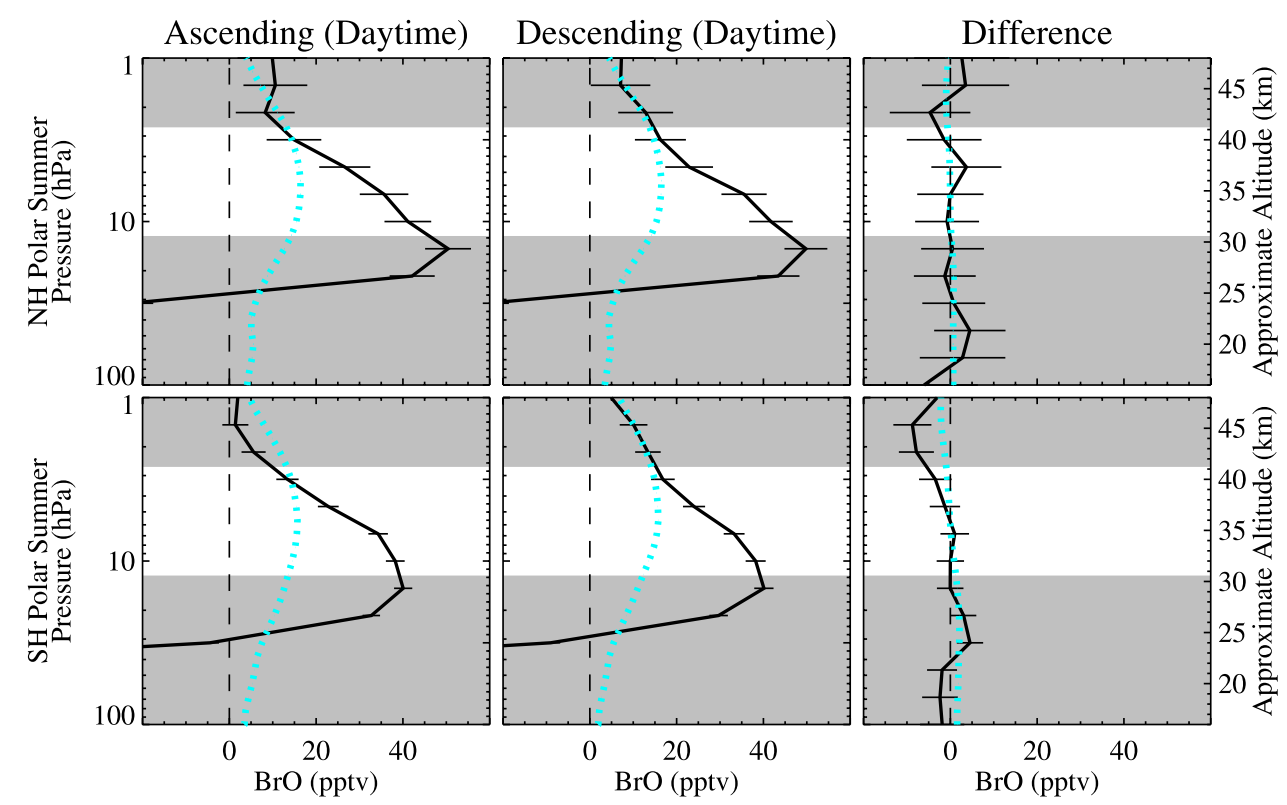

Figure 11. MLS v2.2 BrO vertical profiles for polar summer for ascending (daytime) measurements, descending (also daytime) measurements, and ascending/descending differences (which are expected to be zero). The profiles are seasonal averages of daily zonal means; the error bars show the precision. (top) NH mean for all days (4) reprocessed with MLS v2.2 in June, July, and August 2005 in the latitude range $75^{\circ} \mathrm{N}$ to $82^{\circ} \mathrm{N}$ and (bottom) $\mathrm{SH}$ zonal mean for all days (22) reprocessed with MLS v2.2 in December, January, and February $2004-2005$ in the latitude range $75^{\circ} \mathrm{S}$ to $82^{\circ} \mathrm{S}$. Regions shaded with dark gray indicate where MLS BrO has been determined to be unsuitable for scientific use. Also shown are corresponding SLIMCAT model profiles (cyan).

Optical Absorption Spectrometer (DOAS) instrument [Pfeilsticker et al., 2000; Dorf et al., 2006a]. This instrument detects ultraviolet (UV) and visible light from direct sun measurements during ascent of the balloon and solar occultation. Figure 14 (left) shows a vertical profile of DOAS measurements of $\mathrm{BrO}$ (green points) obtained on
23 March 2003 at $68^{\circ} \mathrm{N}$ [Dorf et al., 2006a] during ascent of the balloon. This flight sampled air both inside and outside the vortex. The solar zenith angle (SZA) for these measurements changes with altitude, ranging from $82^{\circ}$ to $88^{\circ}$. This version of the profile was obtained by smoothing the SCDs (Slant Column Densities) with a Gaussian of full-width-at-
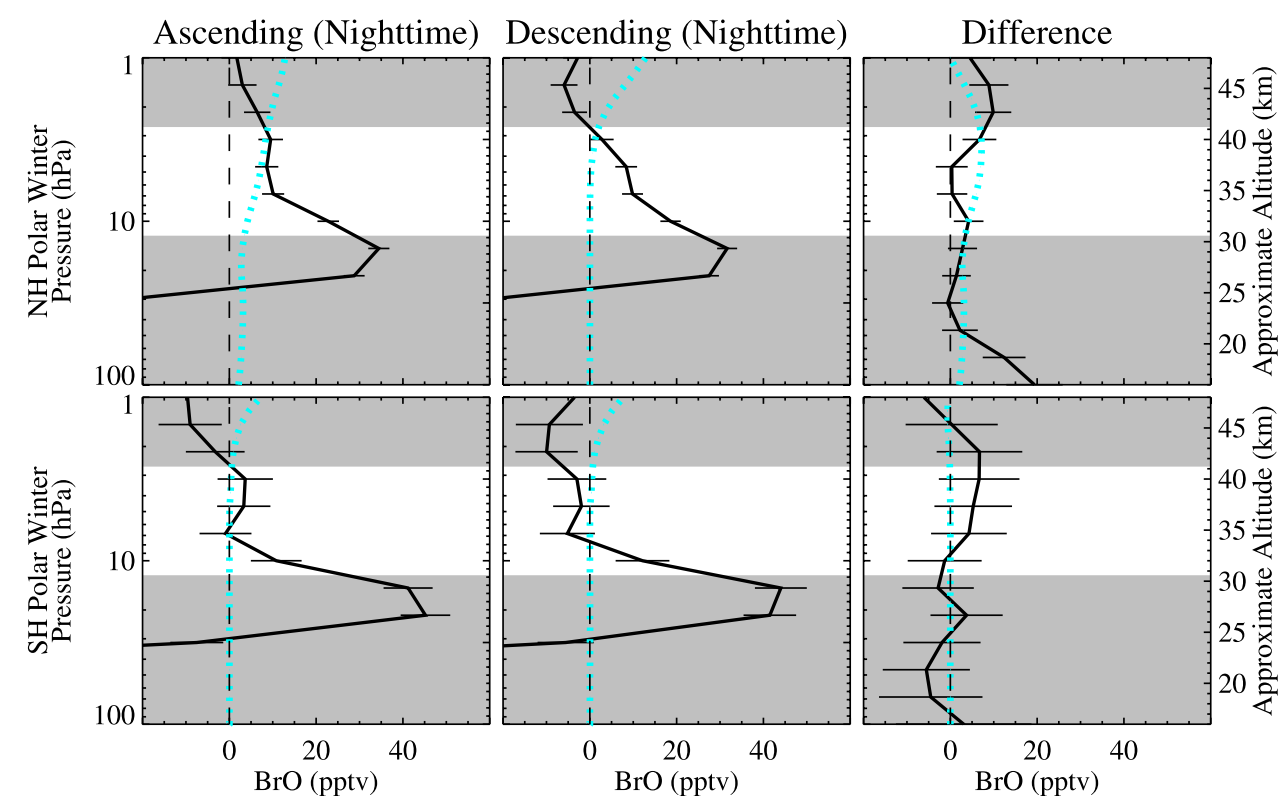

Figure 12. Same as Figure 11 except for polar winter. Regions shaded with dark gray indicate where MLS BrO has been determined to be unsuitable for scientific use. 


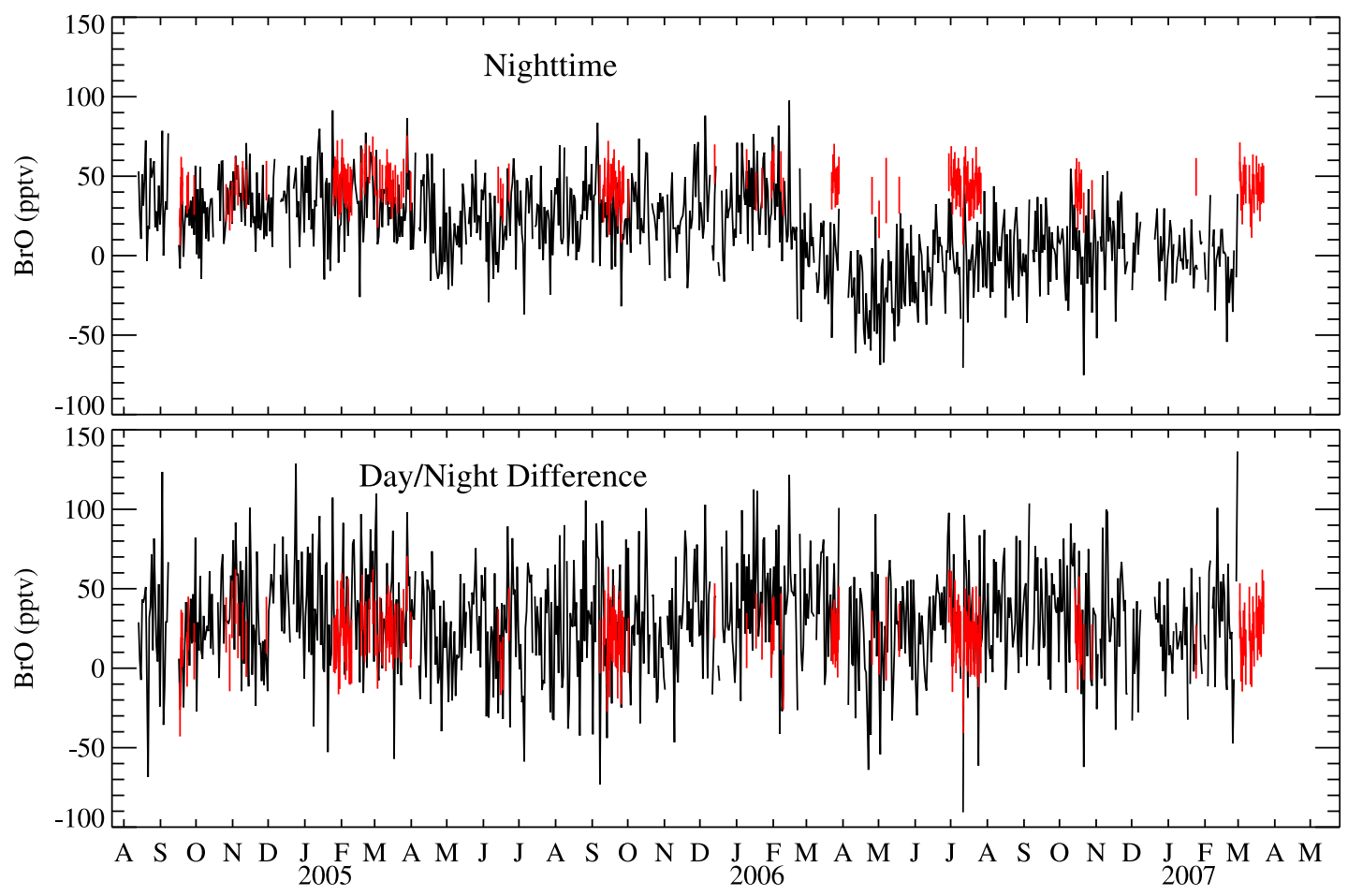

Figure 13. Time series of daily zonal mean $\mathrm{BrO}$ from $35^{\circ} \mathrm{N}$ to $45^{\circ} \mathrm{N}$ for the $10 \mathrm{hPa}$ pressure surface averaged over the duration of the mission. Version 1.5 is shown in black, and v2.2 is shown in red. (top) Nighttime BrO measurements and (bottom) day/night differences. Error bars are shown for v2.2 but not for v1.5. The discontinuity in v1.5 nighttime data seen when band 13 was switched off in March 2006 is not seen in v2.2 nighttime data.

half-max (FWHM) of $1 \mathrm{~km}$ before doing the profile inversion [Dorf, 2005]. The vertical profile of MLS BrO day/ night difference is shown by the black points; the error bars indicate a combination of accuracy and precision. Only those MLS data points in the unshaded region should be compared with the DOAS measurements.

[36] We note some problems with comparing these DOAS measurements of $\mathrm{BrO}$ with the MLS measurements. First, the DOAS measurements were not obtained in the altitude region where the MLS BrO day/night difference measurements are suitable for scientific study (the unshaded region in Figure 14). Second, the high latitude $\left(68^{\circ} \mathrm{N}\right)$ sampled by the DOAS instrument is not included in the average over the MLS measurements, which covers latitudes ranging from $55^{\circ} \mathrm{S}$ to $55^{\circ} \mathrm{N}$. Third, as the two instruments take measurements at different solar zenith angles, we would like to use the PSS model to scale the DOAS BrO, measured at SZAs ranging from $82^{\circ}$ to $88^{\circ}$, to the average SZA of the MLS measurements, about $40^{\circ}$. However, the smallest SZA attained at $68^{\circ} \mathrm{N}$ in March is $65^{\circ}$. Thus the dotted green line shows DOAS BrO scaled to a SZA of $65^{\circ}$, the closest possible to that of MLS BrO. These problems in nonoverlapping altitude range, different SZAs, and different latitudes are overcome by comparing the total inorganic bromine $\left(\mathrm{Br}_{\mathrm{y}}\right)$, which is inferred from the measured $\mathrm{BrO}$ using the PSS model.

[37] Figure 14 (right) compares $\mathrm{Br}_{\mathrm{y}}$ inferred by DOAS $\mathrm{BrO}$ (green dash), to that inferred by MLS BrO day/night difference (black dash). To infer DOAS Br $\mathrm{y}_{\mathrm{y}}$, the PSS model is constrained to DOAS measurements of $\mathrm{NO}_{2}$ and $\mathrm{O}_{3}$. While there are no altitudes for which the DOAS measurements overlap the window of scientifically useful MLS measurements, at this high up in the stratosphere all the organic bromine should have been photochemically converted to $\mathrm{Br}_{\mathrm{y}}$, and so a comparison of $\mathrm{Br}_{\mathrm{y}}$ is still relevant. We see good agreement between the two instruments for inferred $\mathrm{Br}_{\mathrm{y}}, 22.1 \pm 4 \mathrm{ppt}$ for DOAS when averaged over altitude at and above $25 \mathrm{~km}$, and $22.1 \pm 5.5 \mathrm{ppt}$ for MLS when averaged from 10 to $4.6 \mathrm{hPa}$. However, since $\mathrm{Br}_{\mathrm{y}}$ depends on the age of air, which depends on both altitude and latitude, a more meaningful comparison is revealed by plotting the inferred $\mathrm{Br}_{\mathrm{y}}$ vs. the tracer $\mathrm{N}_{2} \mathrm{O}$, which will be shown below.

\subsection{Comparison With SAOZ-BrO BrO}

[38] Figure 15 (left) shows a vertical profile of $\mathrm{BrO}$ (blue points) obtained by the balloon-borne, remote sensing SAOZ-BrO instrument during afternoon ascent of the balloon on 24 August 2004 at $52^{\circ} \mathrm{N}$. SAOZ-BrO is also a solar occultation UV/vis spectrometer [Pundt et al., 2002]. For the SAOZ-BrO measurements, the solar zenith angle ranged from $80^{\circ}$ to $90^{\circ}$. The dotted blue curve is the SAOZ-BrO values scaled to the average SZA $\left(40^{\circ}\right)$ of the MLS measurements using the PSS model. MLS BrO day/night difference measurements are shown by the black points, as in Figure 14. Within the window over which the scientifically useful MLS day/night difference measurements overlap the SAOZ measurements, the measurements agree within respective uncertainties. 


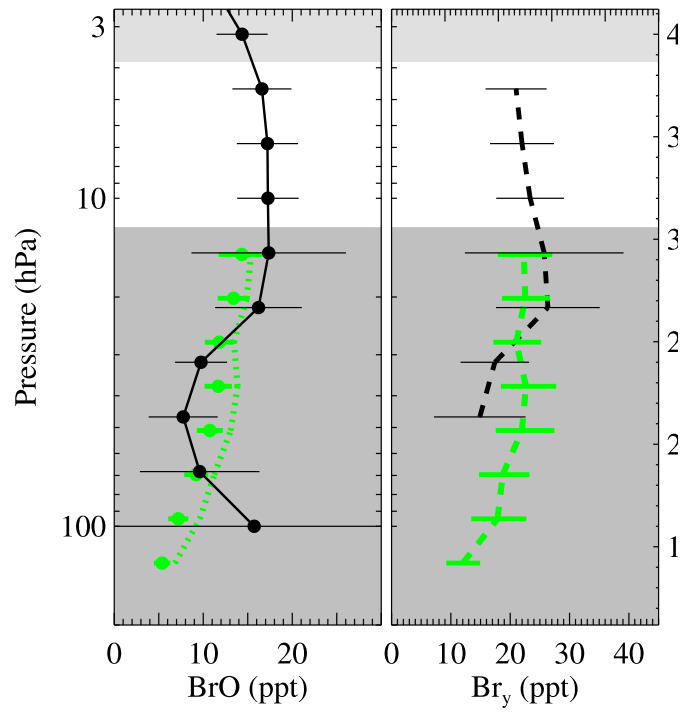

Figure 14. (left) Comparison of MLS day/night difference in $\mathrm{BrO}$ and (right) inferred $\mathrm{Br}_{\mathrm{y}}$ with DOAS data from the 23 March 2003 flight at $68^{\circ} \mathrm{N}$. In Figure 14 (left), the black points show the MLS BrO day/night difference averaged over all days (149) retrieved with v2.2 as of the writing of this manuscript, from $55^{\circ} \mathrm{S}$ to $55^{\circ} \mathrm{N}$. Both the MLS BrO error bars and the DOAS error bars [Dorf et al., 2006a] indicate a combination of precision and accuracy. The average solar zenith angle of the MLS measurements is $40^{\circ}$. The nonshaded region indicates where the day/night difference in MLS BrO is representative of the daytime $\mathrm{BrO}$. The lightly shaded region indicates where the day/ night difference in MLS measurements of $\mathrm{BrO}$ is not representative of daytime $\mathrm{BrO}$; rather, one needs to take account of the nonnegligible nighttime $\mathrm{BrO}$, which we have not done here. The darker shaded region indicates where MLS measurements of $\mathrm{BrO}$ are not suitable for scientific use. The green points show DOAS BrO, while the green dotted curve shows that data scaled using a photochemical model to a SZA of $65^{\circ}$, the smallest SZA attained in March at that latitude. In Figure 14 (right), the dashed black curve is $\mathrm{Br}_{\mathrm{y}}$ inferred from MLS BrO using a photochemical model. The dashed green curve shows $\mathrm{Br}_{\mathrm{y}}$ similarly inferred from DOAS BrO. The error bars on the $\mathrm{Br}_{\mathrm{y}}$ profiles indicate uncertainty due to measured $\mathrm{BrO}$ and $\mathrm{NO}_{2}$, as well as uncertainty in the model kinetics.

[39] Figure 15 (right) shows $\mathrm{Br}_{\mathrm{y}}$ inferred by $\mathrm{SAOZ}-\mathrm{BrO}$ $\mathrm{BrO}$ (blue dash), as well as that inferred by MLS BrO (black dash). To infer SAOZ $\mathrm{Br}_{\mathrm{y}}$, the PSS model is constrained to SAOZ measurements of $\mathrm{NO}_{2}$ and $\mathrm{O}_{3}$. MLS-inferred $\mathrm{Br}_{\mathrm{y}}$ agrees with $\mathrm{SAOZ}$-inferred $\mathrm{Br}_{\mathrm{y}}$ within the respective uncertainties. It should be kept in mind, however, that because of the difference in latitude, SAOZ at $52^{\circ} \mathrm{N}$ while MLS ranging from $55^{\circ} \mathrm{N}$ to $55^{\circ} \mathrm{S}$, the average age of air will be quite different for the two profiles, and thus a more meaningful comparison will be shown below when $\mathrm{Br}_{\mathrm{y}}$ is plotted against $\mathrm{N}_{2} \mathrm{O}$.

\subsection{Comparison With SLS BrO}

[40] Figure 16 (left) shows a vertical profile of $\mathrm{BrO}$ (red points) obtained by the balloon-borne Submillimeter Limb
Sounding (SLS-2) instrument on 20 September 2005 at $34^{\circ} \mathrm{N}$. This is the first vertical profile of $\mathrm{BrO}$ obtained by this instrument, and thus is somewhat preliminary. SLS-2 is a cryogenic heterodyne instrument that detects atmospheric emission [Stachnik et al., 1992]. For BrO it detects the $624.768 \mathrm{GHz}$ lines, corresponding to the ${ }^{81} \mathrm{BrO}$ isotope, the same lines detected by MLS, though MLS also uses the $650 \mathrm{GHz}$ lines. The dotted red curve is the SLS-2 BrO scaled to the local time of the MLS measurements using the PSS model; in this case, since the SLS-2 measurements are obtained in the daytime $\left(\mathrm{SZA}=51^{\circ}\right)$, the scaling makes almost no change to the measured profile. In the window over which the useful MLS measurements overlap the SLS2 measurements, the SLS BrO agrees with MLS at $10 \mathrm{hPa}$, but exceeds MLS BrO by 6 ppt at $4.6 \mathrm{hPa}$, which is outside the range of uncertainty.

[41] Figure 16 (right) shows $\mathrm{Br}_{\mathrm{y}}$ inferred by SLS-2 $\mathrm{BrO}$ (red dashed) and that inferred by MLS BrO (black dashed). To infer SLS-2 $\mathrm{Br}_{\mathrm{y}}$, the PSS model is constrained to FIRS-2 measurements of $\mathrm{NO}_{2}$ and $\mathrm{O}_{3}$. Comparing inferred $\mathrm{Br}_{y}$, MLS and SLS-2 agree within uncertainty. As with the other comparisons, a more meaningful comparison will be shown below when $\mathrm{Br}_{\mathrm{y}}$ is plotted against $\mathrm{N}_{2} \mathrm{O}$.

\subsection{Comparison of $\mathrm{Br}_{\mathrm{y}}$ in Tracer Space}

[42] Figure 17 shows a plot of $\mathrm{Br}_{\mathrm{y}}$ inferred from measurements of $\mathrm{BrO}$ by all four instruments in tracer space (i.e., plotted against $\mathrm{N}_{2} \mathrm{O}$ ). The advantage of this plot is that it accounts for differences in the age of air. The values of $\mathrm{Br}_{\mathrm{y}}$ inferred from MLS BrO are plotted versus MLS measurements of $\mathrm{N}_{2} \mathrm{O}$. For the DOAS curve, the $\mathrm{N}_{2} \mathrm{O}$ was obtained by the Limb Profile Monitor of the Atmosphere (LPMA) instrument, which flew on the same gondola as DOAS. For the $\mathrm{SAOZ}$ curve, the $\mathrm{N}_{2} \mathrm{O}$ is a monthly zonal mean of MLS $\mathrm{N}_{2} \mathrm{O}$ data for that month for the latitude bin $45^{\circ} \mathrm{N}$ to $55^{\circ} \mathrm{N}$. For the SLS- 2 curve, the $\mathrm{N}_{2} \mathrm{O}$ was obtained by the FIRS-2

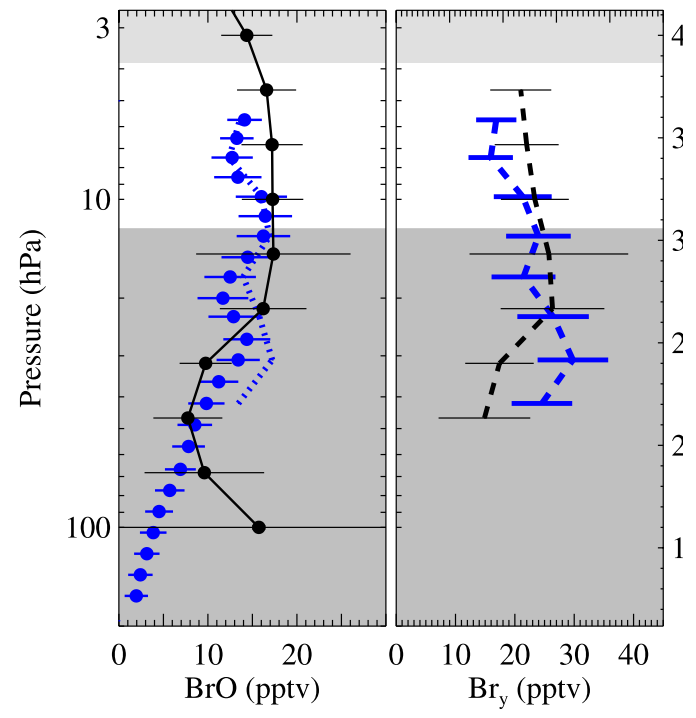

Figure 15. Same as Figure 14 except for $\mathrm{BrO}$ measurements obtained by the SAOZ-BrO instrument (blue) on 24 August 2004 at $52^{\circ} \mathrm{N}$. The MLS BrO error bars indicate a combination of precision and accuracy, and the SAOZ error bars indicate precision. 


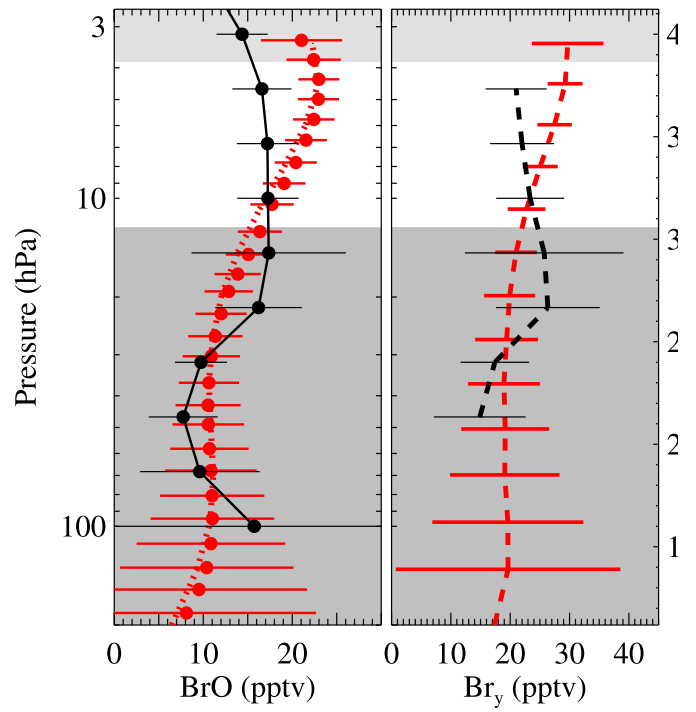

Figure 16. Same as Figure 14 except for $\mathrm{BrO}$ measurements obtained by the SLS-2 instrument (red) on 20 September 2005 at $35^{\circ} \mathrm{N}$. The MLS BrO error bars indicate a combination of precision and accuracy, and the SLS-2 error bars indicate precision. Error bars on MLS and SLS-2 $\mathrm{Br}_{\mathrm{y}}$ have been slightly offset for clarity.

instrument [Chance et al., 1996] aboard the same gondola as SLS-2. Also shown is the "expected" relation (solid cyan) assuming production of $\mathrm{Br}_{\mathrm{y}}$ from only the known organic precursors $\mathrm{CH}_{3} \mathrm{Br}$ and halons [WMO, 2003]. To generate this curve we took the relation in the work by Wamsley et al. [1998] (dashed cyan), which was based on lower-stratospheric measurements of organic source gases obtained in 1994. We then updated the curve to the year of stratospheric entry relevant for this comparison, 2000 (solid line), by scaling the $\mathrm{N}_{2} \mathrm{O}$ and $\mathrm{Br}_{\mathrm{y}}$ to values appropriate for the year $2000[W M O, 2007]$. In the unshaded region of Figure 17, MLS-inferred $\mathrm{Br}_{\mathrm{y}}$ is in agreement with all three of the other measurements within uncertainty. We also note that in this region, the $\mathrm{Br}_{\mathrm{y}}$ inferred from all of the instruments exceeds that expected by the organic source gases. We discuss the implications of this excess $\mathrm{Br}_{\mathrm{y}}$ in the next section.

\subsection{Comparison With SCIAMACHY}

[43] Although the MLS and SCIAMACHY data do not overlap in altitude (SCIAMACHY data is obtained in the lower stratosphere, from about 15 to $30 \mathrm{~km}$ ) we compare the values of total bromine, $\mathrm{Br}_{\mathrm{y}}$, inferred from the measured BrO. SCIAMACHY retrievals by Shoede et al. [2006] infer $18.5 \pm 4 \mathrm{ppt}$, consistent with an earlier estimate of $\mathrm{Br}_{\mathrm{y}}$ from SCIAMACHY BrO by the same group [Sinnhuber et al., 2005]. Retrievals of SCHIAMACHY BrO by Sioris et al. [2006] infer $24.4 \pm 2$ ppt. The $\mathrm{Br}_{\mathrm{y}}$ inferred from MLS BrO is $22.1 \pm 5.5 \mathrm{ppt}$, falling between the two SCIAMACHY retrieval values.

\section{Summary and Implications}

[44] As summarized in Table 2, Aura MLS measurements of $\mathrm{BrO}$ using the v2.2 retrieval are scientifically useful for pressures ranging from $10 \mathrm{hPa}$ to $4.6 \mathrm{hPa}$, provided day/ night differences are taken to remove biases, and significant averaging is done to reduce scatter. A maximum pressure of $10 \mathrm{hPa}$ is chosen because large biases are seen in the nighttime MLS BrO signal at higher pressures. The minimum pressure of $4.6 \mathrm{hPa}$ is chosen because that is the highest pressure for which day/night differences are a good measure of daytime $\mathrm{BrO}$. While the useful pressure range can be extended to the $3.2 \mathrm{hPa}$ pressure surface, the day/ night difference will be a good measure of daytime $\mathrm{BrO}$ only if the nonnegligible nighttime $\mathrm{BrO}$ is taken into account, such as by using a photochemical model to compute the expected diurnal variation. At pressures lower than the $3.2 \mathrm{hPa}$ surface, MLS BrO data are judged unsuitable for scientific study because the day/night differences in the summer polar regions do not behave as expected. For a monthly $10^{\circ}$ zonal mean, over the pressure range from 10 to $3.2 \mathrm{hPa}$, the precision in the day/night difference is \pm 4 ppt and the uncertainty in the accuracy is about $\pm 20 \%$. The vertical resolution between 10 and $3.2 \mathrm{hPa}$ is about $5.5 \mathrm{~km}$.

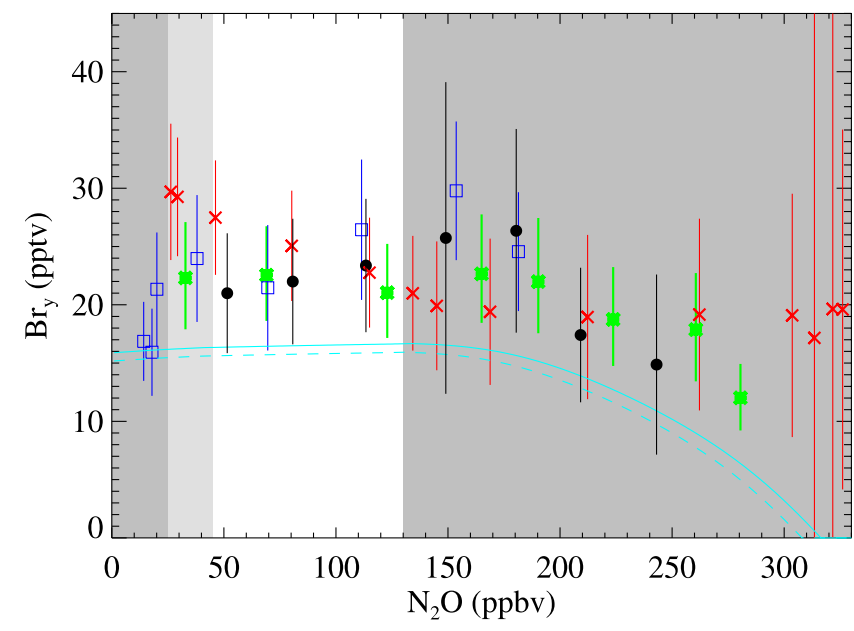

Figure 17. Tracer space comparison of $\mathrm{Br}_{\mathrm{y}}$ inferred from measurements of BrO obtained by MLS and three balloon instruments. The MLS $\mathrm{Br}_{\mathrm{y}}$ (black) is inferred from daily zonal mean $\mathrm{BrO}$ using a photochemical model and then averaged over latitudes ranging from $55^{\circ} \mathrm{S}$ to $55^{\circ} \mathrm{N}$ and over all 149 v2.2 days processed to date. The DOAS (green) $\mathrm{Br}_{\mathrm{y}}$ is inferred from $\mathrm{BrO}$ measured during the March 2003 Kiruna flight, the $\mathrm{SAOZ}-\mathrm{BrO} \mathrm{Br}_{\mathrm{y}}$ (blue) is inferred from $\mathrm{BrO}$ measured during the August 2004 flight, and the SLS-2 inferred $\mathrm{Br}_{\mathrm{y}}$ (red) is for the September 2005 flight. Also shown is the expected relation assuming known organic precursors, based on measurements in 1994 [Wamsley et al., 1998] (dashed cyan) and updated to the year of stratospheric entry of 2000 (solid cyan) [WMO, 2007]. The nonshaded region indicates where the day/night difference in MLS BrO is representative of the daytime $\mathrm{BrO}$. The lightly shaded region, as well as lower $\mathrm{N}_{2} \mathrm{O}$, indicates where the day/night difference in MLS measurements of $\mathrm{BrO}$ is not representative of daytime $\mathrm{BrO}$; rather, one needs to take account of the nonnegligible nighttime $\mathrm{BrO}$. The darker shaded regions indicate where MLS measurements of $\mathrm{BrO}$ are not suitable for scientific use. 
[45] To compare our current retrieval, v2.2, with the interim retrieval used in a previous study [Livesey et al., 2006a], we repeat their calculation of total inorganic bromine, $\mathrm{Br}_{\mathrm{y}}$. In that study, $\mathrm{Br}_{\mathrm{y}}$ was calculated from the MLS interim-version $\mathrm{BrO}$ using the PSS model, and an annual average was taken over latitudes ranging from $55^{\circ} \mathrm{S}$ to $55^{\circ} \mathrm{N}$ and pressures ranging from $10 \mathrm{hPa}$ to $2.2 \mathrm{hPa}$. While day/ night differences were used over the pressure range $10 \mathrm{hPa}$ to $4.6 \mathrm{hPa}$, the ascending measurements were used for the 3.2 and $2.2 \mathrm{hPa}$ pressure levels. Here we again use the PSS model to calculate $\mathrm{Br}_{\mathrm{y}}$ from MLS BrO, except we use v2.2 $\mathrm{BrO}$. We take an average over the same latitude range but only over the days (149) retrieved with v2.2 at the time of writing this manuscript. We use only day/night differences, and average over a smaller pressure range, from $10 \mathrm{hPa}$ to $4.6 \mathrm{hPa}$, where the day/night difference is a good measure of daytime $\mathrm{BrO}$. We find a total stratospheric bromine, $\mathrm{Br}_{\mathrm{y}}$, of $22.1 \pm 5.5 \mathrm{ppt}$, which is in acceptable agreement with the Livesey et al. value of $18.6 \pm 5.5 \mathrm{ppt}$, within the respective uncertainties of each value.

[46] As seen in Figure 17, the $\mathrm{Br}_{\mathrm{y}}$ inferred from MLS measurements of $\mathrm{BrO}$ exceeds the expected value based on the organic precursors $\mathrm{CH}_{3} \mathrm{Br}$ and halons. This is in agreement with mounting evidence that very short lived source gases (VSLS) are contributing significantly to the bromine budget [Pfeilsticker et al., 2000; Salawitch et al., 2005; Dorf et al., 2006b; WMO, 2007]. If we use an estimate of $15.6 \mathrm{ppt}$ for the total bromine abundance of the source gases $\mathrm{CH}_{3} \mathrm{Br}$ and halons present in the atmosphere at the time of the MLS measurements [Montzka et al., 2003; Livesey et al., 2006a], we estimate that the VSLS contribute about $6.5 \pm 5.5 \mathrm{ppt}$ to the bromine budget. Moreover, the agreement of MLS day/night difference $\mathrm{BrO}$ with the SLIMCAT model, seen in Figure 10, also supports this interpretation, since the SLIMCAT model assumed a total inorganic bromine of $22 \mathrm{ppt}$, which represents a contribution of 6 ppt from VSLS.

[47] Our plans for the future include improving the loweraltitude MLS retrievals, where the vertical distribution of stratospheric bromine is currently a controversial issue. While we have some understanding as to the sources of large bias in the MLS BrO data for pressures of $15 \mathrm{hPa}$ and greater, we plan to work on reducing the effect of these sources. In particular, we are looking into a new version of the radiance-based retrieval (called "interim version" in this manuscript) that will be optimized for $\mathrm{BrO}$. (In contrast, the retrieval v2.2 is designed to optimize for the whole of the $640 \mathrm{GHz}$ radiometer.) We also plan to examine retrievals of $\mathrm{BrO}$ in the polar regions, where for summer and winter seasons we cannot use day/night differences. It may be possible to characterize the bias as a function of altitude both for midlatitudes as well as for the polar regions in the spring, and then use this result to compensate for the bias in the polar regions during summer and winter, as was done for MLS ClO by M. L. Santee et al. (Validation of the Aura Microwave Limb Sounder $\mathrm{ClO}$ measurements, submitted to Journal of Geophysical Research, 2007). We do not understand why the day/night difference for the southern polar summer region did not go to zero for pressures of 2.2 and less. We plan to further investigate this issue as well.
[48] Acknowledgments. Research at the Jet Propulsion Laboratory, California Institute of Technology, is performed under contract with NASA. We greatly appreciate the efforts of Bojan Bojkov and the Aura Validation Data Center (AVDC) team, whose work facilitated the MLS validation activities. Thanks to the Aura Project for their support throughout the years (before and after Aura launch), in particular M. Schoeberl, A. Douglass (also as cochair of the Aura validation working group), E. Hilsenrath, and J. Joiner. We also acknowledge the support from NASA Headquarters, P. DeCola for MLS and Aura. The SAOZ team thanks M. van Roozendael (Belgian Institute for Space Aeronomy) for spectra processing, the Canadian Space Agency (CSA), Environment Canada, Scientific Instrumentation Limited, the MANTRA PIs K. Strong and S. Melo (University of Toronto) for flying SAOZ during the MANTRA 2004 campaign, and Centre National d'Etudes Spatiales (CNES) for its financial support.

\section{References}

Bedjanian, Y., et al. (2001), Kinetics and mechanism of the OH and OD reactions with $\mathrm{BrO}, J$. Phys. Chem. A, 105, 6154-6166.

Chance, K., et al. (1996), Simultaneous measurements of stratospheric HOx, NOx, and Clx: Comparison with a photochemical model, J. Geophys. Res., 101, 9031-9043.

Chipperfield, M. (1999), Multiannual simulations with a three-dimensional chemical transport model, J. Geophys. Res., 104, 1781-1805.

Dorf, M. (2005), Investigation of inorganic stratospheric bromine using balloon-borne DOAS measurements and model simulations, Doctor of Natural Sciences thesis, 203 pp., Ruperto Carola Univ. of Heidelberg, Heidelberg, Germany,

Dorf, M., et al. (2006a), Balloon-borne stratospheric BrO measurements: Comparison with Envisat/SCIAMACHY BrO limb profiles, Atmos. Chem. Phys., 6, 2483-2501.

Dorf, M., et al. (2006b), Long-term observations of stratospheric bromine reveal slow down in growth, Geophys. Res. Lett., 33, L24803, doi:10.1029/2006GL027714.

Drouin, B. J., et al. (2001), The rotational spectra, isotopically independent parameters, and interatomic potentials for the $\mathrm{X}_{1}^{2} \prod_{3 / 2}$ and $\mathrm{X}_{2}^{2} \prod_{1}$ states of BrO, J. Molec. Spectrosc., 205, 128-138.

Frieler, K., et al. (2006), Toward a better quantitative understanding of polar stratospheric ozone loss, Geophys. Res. Lett., 33, L10812, doi:10.1029/ 2005GL025466.

Livesey, N. J., and W. G. Read (2000), Direct retrieval of line-of-sight atmospheric structure from limb sounding observations, Geophys. Res. Lett., 27, 891-894.

Livesey, N. J., et al. (2006a), EOS Microwave Limb Sounder observations of upper stratospheric BrO: Implications for total bromine, Geophys. Res. Lett., 33, L20817, doi:10.1029/2006GL026930.

Livesey, N. J., et al. (2006b), Retrieval algorithms for the EOS Microwave Limb Sounder (MLS), IEEE Trans. Geosci. Remote Sens., 44, 11441155 .

McElroy, M. B., et al. (1986), Reductions of Antarctic ozone due to synergistic interactions of chlorine and bromine, Nature, 321, 759-762.

Montzka, S. A., J. H. Butler, B. D. Hall, D. J. Mondeel, and J. W. Elkins (2003), A decline in tropospheric organic bromine, Geophys. Res. Lett., 30(15), 1826, doi:10.1029/2003GL017745.

Osterman, G. B., et al. (1997), Balloon-borne measurements of stratospheric radicals and their precursors: Implications for the production and loss of ozone, Geophys. Res. Lett., 24, 1107-1110.

Pfeilsticker, K., et al. (2000), Lower stratospheric organic and inorganic bromine budget for the Arctic winter 19 98/99, Geophys. Res. Lett., 27, $3305-3308$

Pundt, I., J.-P. Pommereau, M. P. Chipperfield, M. Van Roozendael, and F. Goutail (2002), Climatology of the stratospheric BrO vertical distribution by balloon-borne UV-visible spectrometry, J. Geophys. Res., 107(D24), 4806, doi:10.1029/2002JD002230.

Read, W. G., et al. (2007), Aura Microwave Limb Sounder upper tropospheric and lower stratospheric $\mathrm{H}_{2} \mathrm{O}$ and RHi validation, J. Geophys. Res., doi:10.1029/2007JD008752, in press.

Rodgers, C. D. (2000), Inverse Methods for Atmospheric Science, Theory and Practice, World Sci., Hackensack, N. J.

Salawitch, R. J., et al. (2005), Sensitivity of ozone to bromine in the lower stratosphere, Geophys. Res. Lett., 32, L05811, doi:10.1029/ 2004GL021504

Sander, S. P., et al. (2003), JPL 2002: Chemical kinetics and photochemical data for use in atmospheric studies, evaluation 14, JPL Publ. 02-25, Jet Propul. Lab., Pasadena, Calif.

Sander, S. P., et al. (2006), JPL 2006: Chemical kinetics and photochemical data for use in atmospheric studies, evaluation 15, JPL Publ. 06-2, Jet Propul. Lab., Pasadena, Calif. 
Sheode, N., et al. (2006), Toward a climatology of stratospheric bromine monoxide from SCIAMACHY limb observations, Atmos. Chem. Phys. Disc., 6, 6431-6466.

Sinnhuber, B.-M., et al. (2005), Global observations of stratospheric bromine monoxide from SCIAMACHY, Geophys. Res. Lett., 32, L20810, doi:10.1029/2005GL023839.

Sinnhuber, B.-M., et al. (2006), The contribution of anthropogenic bromine emissions to past stratospheric ozone trends: A modelling study, Atmos. Chem. Phys. Disc., 6, 6497-6524.

Sioris, C. E., et al. (2006), Latitudinal and vertical distribution of bromine monoxide in the lower stratosphere from Scanning Imaging Absorption Spectrometer for Atmospheric Chartography limb scattering measurements, J. Geophys. Res., 111, D14301, doi:10.1029/2005JD006479.

Soller, R., et al. (2001), Temperature-dependent rate coefficients for the reactions of $\mathrm{Br}\left({ }^{2} \mathrm{P}_{3 / 2}\right), \mathrm{Cl}\left({ }^{2} \mathrm{P}_{3 / 2}\right)$, and $\left.\mathrm{O}\left({ }^{3} \mathrm{P}_{\mathrm{J}}\right)\right)$ with $\mathrm{BrONO}_{2}, J$. Phys Chem. A, 105, 1416-1422.

Stachnik, R. A., et al. (1992), Submillimeter wave heterodyne measurements of stratospheric $\mathrm{ClO}, \mathrm{HCl}, \mathrm{O}_{3}$, and $\mathrm{HO}_{2}$ : 1st results, Geophys. Res. Lett., 19, $1931-1934$.

Wamsley, P. R., et al. (1998), Distribution of halon-1211 in the upper troposphere and lower stratosphere and the 1994 total bromine budget, J. Geophys. Res., 103, 1513-1526.

Waters, J. W., et al. (2006), The Earth Observing System Microwave Limb Sounder (EOS MLS) on the Aura satellite, IEEE Trans. Geosci. Remote Sens., 44, 1075-1092.

World Meteorological Organization (2003), Scientific assessment of ozone depletion: 2002, Global Ozone Res. and Monit. Proj., Rep. 47, Geneva, Switzerland.
World Meteorological Organization (2007), Scientific assessment of ozone depletion: 2006, Global Ozone Res. and Monit. Proj., Rep. 50, Geneva, Switzerland

Yamada, M. M., et al. (2003), Submillimeter-wave measurements of the pressure broadening of BrO, J. Quant. Spectrosc. Radiat. Transfer, 82, 391-399.

Yung, Y. L., et al. (1980), Atmospheric bromine and ozone perturbations in the lower stratosphere, J. Atmos. Sci., 37, 339-353.

C. Camy-Peyret, Laboratoire de Physique Moleculaire pour l'Atmosphere et l'Astrophysique, Universite Pierre et Marie Curie, F-75252 Paris, France.

M. P. Chipperfield, Institute of Atmospheric Science, School of Earth and Environment, University of Leeds, Leeds LS2 9JT, UK.

R. E. Cofield, B. J. Drouin, L. Froidevaux, R. A. Fuller, R. F. Jarnot, B. W. Knosp, L. J. Kovalenko, A. Lambert, N. L. Livesey, W. G. Read, M. L. Santee, M. J. Schwartz, W. V. Snyder, R. Stachnik, Stek, P. A. Wagner, and J. W. Waters, Jet Propulsion Laboratory, California Institute of Technology, Pasadena, CA 91109, USA.

M. Dorf and K. Pfeilsticker, Institute of Environmental Physics, University of Heidelberg, D-69120 Heidelberg, Germany.

F. Goutail and J.-P. Pommereau, Service d'Aeronomie, Centre National de la Recherche Scientifique, F-91371 Verrieres-le-Buisson, France.

K. Jucks, Harvard-Smithsonian Center for Astrophysics, Cambridge, MA 02138, USA.

I. A. MacKenzie, School of GeoSciences, University of Edinburgh, Edinburgh EH8 9YL, UK.

R. J. Salawitch, Department of Atmospheric and Oceanic Science, 2403 Computer and Space Sciences Building, University of Maryland, College Park, MD 20742, USA 